\title{
Medicina tradicional en la comunidad de San Basilio de Palenque
}

\author{
Traditional medicine in the community of San Basilio de Palenque
}

Ronald Fernando Quintana Arias ${ }^{1}$

\section{Resumen}

Objetivo. Identificar plantas con valor de uso medicinal usadas en la comunidad de San Basilio de Palenque entre el 2009 y el 2014. Metodología. Se utilizó el enfoque metodológico consenso de informantes. Resultados. Se registró el uso medicinal de 135 plantas, de las cuales se identificaron 57 especies y 124 géneros pertenecientes a 58 familias botánicas. Lo anterior permitió establecer la relación entre la historia social de usos medicinales que vincula a África y América, así como una clasificación por temperaturas (frío-caliente) que enlazan directamente el ciclo de vida de la planta, el territorio y el cuerpo humano. Los resultados indican una relación ser humano-territorio-uso medicinal, lo que determina la posología del tratamiento y el ciclo vital de la planta.

Palabras clave: Afrocolombiano, categorías térmicas, etnobotánica, ser humano, territorio, uso medicinal.

\section{Abstract}

Objective. Identify plants with value of medicinal use in the community of San Basilio de Palenque between 2009 and 2014. Methods. It was used the informants consensus methodological approach. Results. It was registered 135 medicinal plants, of which 57 species and 124 genera belonging to 58 botanical families were identified. This allowed to establish the relationship between social history of medicinal uses linking Africa and America, as well as a classification temperature (cold-hot) that directly link the life cycle of the plant, the territory and the human body. The results indicate a relationship between human being-territory-medicinal use, which determines the dosage of the treatment and the life cycle of the plant.

Keywords: Afro-Colombian, thermal categories, ethnobotany, human being, territory, medicinal use.

'B.sc, Magister en Desarrollo Sustentable y Gestión Ambiental - Universidad el Bosque, Investigador ONG Makunagua

Correspondencia: ron902102004@gmail.com

orcid.org/0000-0002-3691-3464

Recibido: 02-01-2016 Aceptado: 15-05-2016 


\section{Introducción}

En Latinoamérica el estudio de los sistemas médicos tradicionales inicia formalmente en 1951, cuando el instituto de antropología social del "Smithsonian Institution" de Washington estudia en Colombia, México, Brasil y Perú los principios básicos que gobiernan la conducta médica en las sociedades campesinas y urbanas. El resultado de dicho estudio arrojó un cuerpo coherente y homogéneo de prácticas y creencias comunes en los cuatro países (1).

Las propuestas sobre medicina tradicional han prosperado sobre todo en África y Asia y como resultado en 1998 se realizó la consulta internacional de conservación de plantas Medicinales, de la que se emitió en Tailandia la declaración de "Chiang Mai" en donde se enfatiza la importancia de los conocimientos tradicionales para garantizar la atención primaria en salud. Esto generó la declaración "Salve vidas, salvando plantas", la cual representa el punto de partida para una reflexión entre la relación entre la naturaleza y la salud (2).

El término "medicina tradicional" se empleó por primera vez durante la reunión de Alma-Ata en la cual se dio una primera definición: "se entiende por medicina tradicional la suma de todos los conocimientos teóricos y prácticos, explicables o no, utilizados para diagnóstico, prevención y supresión de trastornos físicos, mentales o sociales basados exclusivamente en la experiencia y en la observación trasmitidos verbalmente o por escrito de una generación a otra" (3).

El término no ha sido aceptado en forma unánime. Algunos autores hablan de conocimientos como sabiduría popular, otros de personas como sabedores tradicionales. Lo quesehageneralizado es la dicotomía ciencia-conocimientos tradicionales: "designan como hechos sociales grandes sistemas de conocimiento, de un lado, el de la sociedad moderna $y$ de otro el de las sociedades tradicionales" (4). "Actualmente los conocimientos tradicionales tienen un reconocimiento jurídico internacional a pesar de no contar con este en el ámbito de la ciencia occidental y de la academia, se habla entonces del dilema de aceptar o rechazar el origen de los conocimientos, el método o los resultados" (5).

Perdersen (6) sugiere diferenciar el sistema médico y el sistema de salud al considerar que el primero es un conjunto organizado de recursos humanos, tecnologías y servicios específicamente destinados al desarrollo y práctica de una medicina para la atención de la salud individual o colectiva, mientras entiende por sistema de salud el conjunto de elementos o componentes del sistema social más amplio relacionados con la salud y el bienestar físico, mental y social de la población. Según Zuluaga y Correa (5) para que una medicina sea considerada como tradicional, debe cumplir con el requisito de tener arraigo histórico, cultural y social en la tradición del pueblo. Es por esto que la medicina tradicional se define en concordancia con la tradición del que la utilice, por lo que se puede hablar de diferentes medicinas tradicionales según se haga referencia.

Lo anterior hace pertinente establecer que la medicina tradicional latinoamericana y la relación salud-naturaleza-cultura es un producto del legado indígena, afro-descendiente y español, caracterizado por nociones religiosas de salud y conceptos de frio-calor como causa de muchas enfermedades (7). Lo anterior da origen al humoralismo que establece fluctuaciones entre cualidades intangibles denominadas humores (8-9).

Algunos estudios como el de Colson \& Armellada (10) hablan de estos humores dentro de una clasificación binaria frío-calor propia de los pueblos latinoamericanos, al relacionar plantas medicinales, enfermedades, humedad y sequedad (11). Es de resaltar que estudios en el pueblo Bantú de África, del que según Friedemann (12), provienen la mayor parte de los afrodescendientes colombianos, recurre a estas categorías térmicas en la utilización de las plantas medicinales (13-14).

En el contexto afrocolombiano, la clasificación frío-caliente se ha establecido en comunidades de 
Nariño (15), Valle del Cauca (16), Chocó (1718) y San Basilio de Palenque (19-21) en los que se ha ampliado la categorización de lo vegetal y las enfermedades, al entendimiento del cuerpo humano y la relación entre la vida y la muerte en un sistema cultural y espiritual, lo que ha influido no solo a la región caribe, sino le ha conferido el reconocimiento cultural de toda la nación.

Este artículo se basa en un estudio descriptivo con un enfoque mixto, en donde lo cualitativo es conformado por los usos reportados por la comunidad y lo cuantitativo se basa en el número de plantas identificadas. Se buscó establecer un canal semiótico en dos vías estableciendo: nombres vernáculos de las plantas, familias taxonómicas más importantes, reporte de usos para las familias taxonómicas y categorías térmicas. Se colectaron y/o fotografiaron 135 plantas medicinales, de las cuales se identificaron 57 especies y 124 géneros pertenecientes a 58 familias taxonómicas.

\section{Caracterización de la comunidad}

El primer pueblo libre de América conocido como San Basilio de Palenque (la comunidad no acepta que se diga Palenque de San Basilio ya que el pueblo no es del santo sino el santo es del pueblo) se originó en la época de la colonia cuando en respuesta a la esclavitud algunos grupos de negros cimarrones rebeldes escaparon y se organizaron con el liderazgo de Benkos Bioho (antiguo príncipe de una tribu africana, quien lideró la fuga y la posterior lucha por la libertad de estos pueblos en el territorio colombiano), obteniendo el reconocimiento de su autonomía por parte de la corona española en el siglo XVI (22-25).

Actualmente Palenque representa solo el 0,1\% de la población afrodescendiente del país y es reconocida por la UNESCO como Obra Maestra del Patrimonio Oral e Inmaterial de la Humanidad (26). Está ubicado en el departamento de Bolívar (se ubica a $50 \mathrm{Km}$. al sur oriente de la ciudad de Cartagena de Indias), a unos 100 msnm en un bosque seco tropical del cinturón Árido
Pericaribeño, en un valle de vegetación variada (27) formado por los Montes de María, con una temperatura media de $30^{\circ} \mathrm{C}(28-29)$.

En la comunidad habitan aproximadamente 3.500 personas pertenecientes a cerca de 400 familias repartidas en un poco más de 400 viviendas. Sin embargo, existe también población palenquera fuera de este territorio y actualmente puede llegar a 10.000 personas quienes viven en ciudades de la región como Cartagena (50\%); Barranquilla (39\%); Caracas, Venezuela (6\%), el centro del país (4\%) y Maicao (1\%) (27).

Las relaciones ecológicas con el entorno establecen un modelo de producción regulado por los ciclos de la luna. De acuerdo con Restrepo \& Natividad (30) la luna llena (buena o madura) es ideal para sembrar, recolectar, cultivar y preparar plantas; mientras que la luna mala o biche es ideal para preparar las parcelas de los cultivos, lo que es determinante para el desarrollo de la economía local que se basa en cultivos de yuca, maíz y ñame, ganadería en el monte (leche y carne), productos vegetales y animales provenientes de los patios; así como la comercialización tradicionalmente por parte de las mujeres de quesos o bollos de maíz, carnes (puerco, res, pescado) y productos de las labores agrícolas, en los poblados y ciudades circunvecinas (30).

La organización social se fundamenta en la organización de "Kuagros" (Grupos de edad que se constituyen desde la infancia y perduran a través de la vida de los individuos) y "Juntas" (reuniones de participación abierta en la comunidad) (29). La población se divide entre la gente del poblado y la del monte. Las primeras son aquellas que se encuentran cerca de la iglesia, parque, centro de salud, establecimientos escolares y el cementerio. Las segundas son las que viven donde se llevan a cabo las actividades agrícolas y ganaderas, el cual a su vez es un espacio predominantemente masculino. Asimismo, el poblado se divide en el barrio de abajo (Bajeros) y el barrio de arriba (Riveros), lo que ha marcado una rivalidad ya que 
el Rivero se asocia con la tradición y al Bajero con el mundo exterior (30).

En cuanto a las relaciones familiares se establece la importancia de la descendencia del padre y de la madre. Muestra de ello es que a pesar de la poligamia (este comportamiento se permite exclusivamente para los hombres y establece que las mujeres de los hombres deben vivir en casas separadas) por parte de los hombres, todos los hijos e hijas son considerados iguales en términos de deberes y derechos con respecto a sus padres (30-31).

Por otro lado, sobresalen las manifestaciones culturales. La comunidad posee una de las dos lenguas criollas de estrato hispánico que se hablan en el mundo, es la única lengua creole (cuando la segunda lengua de los padres se convierte en la primera lengua de los hijos) con una marcada influencia bantú que se habla en los pueblos afrodescendientes de Colombia.

Las festividades se caracterizan por la música y presentan un sincretismo entre el catolicismo y las lógicas culturales de la comunidad, en la que sobresale el ciclo de la muerte.

En este sentido se considera que el canto de las aves oscuras como el kajambá, el kambamba y el lombo-lombo son medios para hacer pactos con el diablo para convertirse en bularias o brujas que vuelan (3132), y que en el ritual del lumbalú (el prefijo kikongo lu, más el término mbalú, significan "memoria, recolección, pensamiento") nueve días después del velorio tanto los dolientes y el kuagro se enfoquen en las prácticas rituales y suspendan sus actividades cotidianas; ya que de no hacerse los rituales, el difunto no estará contento (23) y no descansará en paz (32).

\section{Metodología}

La propuesta realizada a través de la ONG Makunagua pretendió generar elementos para promover y rescatar algunos conocimientos relacionados con el uso de las plantas medicinales en la comunidad. Se aplicó en primera medida el enfoque metodológico basado en el "Consenso de Informantes", metodología desarrollada por Adu-Tutu et al., (33); Phillips \& Gentry (34); y Phillips (35), ya que permite realizar la evaluación cuantitativa de la importancia del uso de las plantas dentro de la comunidad y da mayor probabilidad de encontrar plantas con actividad farmacológica que aquellas seleccionadas al azar o por criterios quimiotaxonómicos (36-37). La muestra documental se obtuvo a partir de herramientas de tipo etnográfico como encuestas, entrevistas semiestructuradas, recorridos y registro fotográfico.

Las encuestas para identificación de los sabedores se basaron en el estudio etnobotánico el "verdadero" guardián del oro verde Quintana (38), así como el de plantas y dueños Quintana (7), lo que arrojó una estimación de 50 sabedores de medicina tradicional, llegándose a lograr acuerdos de trabajo con 14\% lo que está por encima del 10\% que es considerado deseable dentro del tamaño muestral (39). Asimismo, las entrevistas semiestructuradas realizadas a los sabedores fueron el indicativo que sirvió para la determinación de las categorías térmicas y medicinales presentadas en los resultados de esta investigación.

La metodología se dividió en tres fases: campo (tres meses), laboratorio (dos meses) y análisis (24 meses). La fase de campo se realizó en la comunidad, con una serie de acciones: presentación de la propuesta de investigación a la comunidad, identificación de los sabedores, inventario de las plantas de uso medicinal reportadas por los sabedores, identificación de los usos de las plantas asociadas a las enfermedades por los diferentes sabedores, recolección de plantas reportadas así como la realización de un registro fotográfico de la especies, lo que llevó a una identificación científica preliminar apoyada en textos botánicos (40).

Para la fase de laboratorio y análisis, se realizó en un primer momento el secado de muestras vegetales obtenidas en la comunidad (50 ejemplares) en el herbario de la Universidad Distrital Francisco José de Caldas (sede vivero). En otro momento de la investigación se decidió solo optar por el registro fotográfico, como una manera de proteger la biodiversidad vegetal, lo 
que llevó a la identificación de especies del $40.1 \%$ de la muestra de 135 plantas, cuyo análisis estableció la visión de "agroecológica sociocultural" (41).

\section{Resultados}

En este apartado se exponen y analizan los resultados de 135 plantas pertenecientes a 58 familias taxonó- micas, determinadas hasta género vegetal (100\%) y especie (42.22\%) para un total de 253 aplicaciones medicinales en los que se especifican: nombre vernáculo; parte usada; forma de preparación; administración; categoría térmica dentro de la comunidad (ver Tabla 1). Asimismo, los análisis evidencian la relación entre la historia, ser humano-territorio-uso medicinal y como ésta determina la posología del tratamiento, así como el ciclo vital de la planta.

Tabla 1. Plantas de uso medicinal en San Basilio de Palenque

\begin{tabular}{|c|c|c|c|c|c|c|c|c|c|}
\hline Familia & Género & Especie & $\begin{array}{l}\text { Nombre } \\
\text { Vernáculo }\end{array}$ & $\begin{array}{l}\text { Parte } \\
\text { usada }\end{array}$ & Uso popular & $\begin{array}{l}\text { Propiedad } \\
\text { medicinal }\end{array}$ & Preparación & Administración & $\begin{array}{c}\text { Categoría } \\
\text { térmica }\end{array}$ \\
\hline \multirow{5}{*}{ 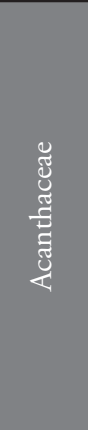 } & \multirow{2}{*}{ Aphelandra } & & \multirow{2}{*}{ Aventurero } & Hojas & Mal de ojo & $\begin{array}{l}\text { Mágico- } \\
\text { religiosa }\end{array}$ & Decocción & Baños & Fría \\
\hline & & & & Hojas & Fiebre & $\begin{array}{l}\text { Antipirética o } \\
\text { febrífuga }\end{array}$ & Decocción & Baños & Fría \\
\hline & \multirow{2}{*}{ Bravaisia } & \multirow{2}{*}{$\begin{array}{l}\text { Bravaisia } \\
\text { integerrima }\end{array}$} & \multirow{2}{*}{$\begin{array}{l}\text { Palo de } \\
\text { agua }\end{array}$} & Hojas & $\begin{array}{l}\text { Dolor de } \\
\text { cabeza }\end{array}$ & $\begin{array}{l}\text { Analgésico o } \\
\text { calmante }\end{array}$ & Decocción & Baños & Fría \\
\hline & & & & Hojas & Fiebre & $\begin{array}{c}\text { Antipirética o } \\
\text { febrífuga }\end{array}$ & Decocción & Baños & Fría \\
\hline & Justicia & & $\begin{array}{c}\text { San } \\
\text { Gregorio }\end{array}$ & Hojas & Riñones & Diuréticas & Decocción & Oral & Fría \\
\hline \multirow{3}{*}{ 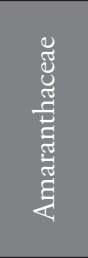 } & \multirow{2}{*}{ Amaranthus } & & \multirow{2}{*}{$\begin{array}{l}\text { Belo de } \\
\text { puerco }\end{array}$} & Hojas & $\begin{array}{l}\text { Debilidad en } \\
\text { la sangre }\end{array}$ & Depuración & Decocción & Oral & Fría \\
\hline & & & & Hojas & $\begin{array}{c}\text { Dolencias en } \\
\text { el cuerpo }\end{array}$ & $\begin{array}{l}\text { Analgésico o } \\
\text { calmante }\end{array}$ & Decocción & Oral & Fría \\
\hline & Chamissoa & & Uvitilla & Hojas & Golpes & $\begin{array}{l}\text { Emoliente, } \\
\text { antiflogístico }\end{array}$ & Chapeo & Cataplasma & Fría \\
\hline \multirow{5}{*}{ 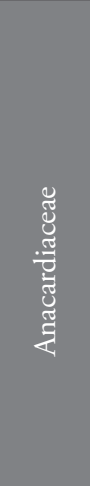 } & Spondias & $\begin{array}{l}\text { Spondias } \\
\text { mombin }\end{array}$ & Hobo & $\begin{array}{l}\text { Fruto y } \\
\text { cogollo }\end{array}$ & Conjuntivitis & Oftálmica & Cruda & Tópica & Fría \\
\hline & \multirow{3}{*}{ Mangifera } & \multirow{3}{*}{$\begin{array}{l}\text { Mangifera } \\
\text { indica }\end{array}$} & \multirow{3}{*}{ Mango } & Hojas & $\begin{array}{l}\text { Dolor de } \\
\text { estómago }\end{array}$ & $\begin{array}{l}\text { Analgésico o } \\
\text { calmante }\end{array}$ & Decocción & Oral & $\begin{array}{c}\text { Caliente } \\
\text { y fría }\end{array}$ \\
\hline & & & & Hojas & $\begin{array}{l}\text { Presión } \\
\text { arterial }\end{array}$ & vasodilatadora & Decocción & Oral & $\begin{array}{c}\text { Caliente } \\
\text { y fría }\end{array}$ \\
\hline & & & & Hojas & $\begin{array}{l}\text { Presión } \\
\text { arterial }\end{array}$ & & Decocción & Oral & $\begin{array}{c}\text { Caliente } \\
\text { y fría }\end{array}$ \\
\hline & Astronium & $\begin{array}{l}\text { Astronium } \\
\text { graveolens }\end{array}$ & Santa Cruz & Hojas & $\begin{array}{l}\text { Dolor de } \\
\text { cabeza }\end{array}$ & $\begin{array}{c}\text { Analgésico o } \\
\text { calmante }\end{array}$ & Decocción & Baños & Caliente \\
\hline $\begin{array}{l}\underset{\Xi}{\Xi} \\
\tilde{\Xi} \\
0 \\
\vdots\end{array}$ & Annona & $\begin{array}{l}\text { Annona } \\
\text { muricata }\end{array}$ & Guanábana & Hojas & $\begin{array}{l}\text { Reposar el } \\
\text { cuerpo }\end{array}$ & $\begin{array}{l}\text { Analgésico o } \\
\text { calmante }\end{array}$ & Decocción & Oral y Bańos & Fría \\
\hline
\end{tabular}




\begin{tabular}{|c|c|c|c|c|c|c|c|c|c|}
\hline Familia & Género & Especie & $\begin{array}{l}\text { Nombre } \\
\text { Vernáculo }\end{array}$ & $\begin{array}{l}\text { Parte } \\
\text { usada }\end{array}$ & Uso popular & $\begin{array}{l}\text { Propiedad } \\
\text { medicinal }\end{array}$ & Preparación & Administración & $\begin{array}{l}\text { Categoría } \\
\text { térmica }\end{array}$ \\
\hline \multirow{3}{*}{ 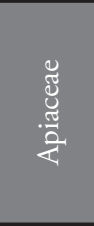 } & \multirow{3}{*}{ Eryngium } & \multirow{3}{*}{$\begin{array}{l}\text { Eryngium } \\
\text { Foetidum }\end{array}$} & \multirow{3}{*}{ Culantro } & Hojas & Brujería & $\begin{array}{l}\text { Mágico- } \\
\text { religiosa }\end{array}$ & Cruda & Oral & Fría \\
\hline & & & & Hojas & Purgante & $\begin{array}{l}\text { Tenífuga o } \\
\text { Vermífuga }\end{array}$ & Cruda & Oral & Fría \\
\hline & & & & Hojas & Insomnio & Sedante & Cruda & Oral & Fría \\
\hline 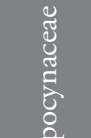 & Thevetia & $\begin{array}{l}\text { Thevetia } \\
\text { peruviana }\end{array}$ & Cabalonga & Semillas & $\begin{array}{l}\text { Contra de } \\
\text { brujas }\end{array}$ & $\begin{array}{l}\text { Mágico- } \\
\text { religiosa }\end{array}$ & Cruda & No aplica & Fría \\
\hline \multirow{6}{*}{ 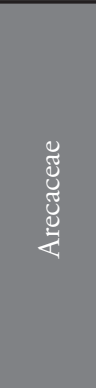 } & \multirow{4}{*}{ Elaeis } & \multirow{4}{*}{$\begin{array}{l}\text { Elaeis } \\
\text { oleifera }\end{array}$} & \multirow{4}{*}{ Coroza } & Fruto & Alopecia & Tónico & Decocción & Tópica & Fría \\
\hline & & & & Fruto & Inflamación & $\begin{array}{c}\text { Antiflogístico } \\
\text { Emoliente }\end{array}$ & Decocción & Tópica & Fría \\
\hline & & & & Fruto & Quemadura & Vulneraria & Decocción & Tópica & Fría \\
\hline & & & & Fruto & Colesterol & $\begin{array}{l}\text { Anti- } \\
\text { colesterol }\end{array}$ & Decocción & Tópica & Fría \\
\hline & \multirow{2}{*}{ Bactris } & & \multirow{2}{*}{ Lata } & Pulpa & Murciélagos & Repelente & Decocción & Oral & Fría \\
\hline & & & & Pulpa & Líquidos & Diurética & Decocción & Oral & Fría \\
\hline \multirow{7}{*}{ 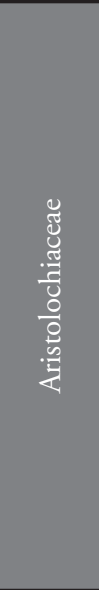 } & \multirow{7}{*}{ Aristolocia } & & \multirow{3}{*}{ Capitana } & $\begin{array}{l}\text { Planta } \\
\text { entera }\end{array}$ & $\begin{array}{l}\text { Mordedura } \\
\text { de serpiente }\end{array}$ & Antiofídica & Raspado & Oral & Caliente \\
\hline & & & & $\begin{array}{l}\text { Planta } \\
\text { entera }\end{array}$ & $\begin{array}{l}\text { Dolor de } \\
\text { estomago }\end{array}$ & $\begin{array}{c}\text { Analgésico o } \\
\text { calmante }\end{array}$ & Raspado & Oral & Caliente \\
\hline & & & & $\begin{array}{l}\text { Planta } \\
\text { entera }\end{array}$ & $\begin{array}{c}\text { Dolor de } \\
\text { cabeza }\end{array}$ & $\begin{array}{l}\text { Analgésico o } \\
\text { calmante }\end{array}$ & Raspado & Oral & Caliente \\
\hline & & & \multirow{4}{*}{$\begin{array}{l}\text { Capitana } \\
\text { Mayor }\end{array}$} & Corteza & $\begin{array}{l}\text { Mordedura } \\
\text { de serpiente }\end{array}$ & Antiofídica & Decocción & Oral y Tópico & Caliente \\
\hline & & & & Corteza & Vomitar & Vomitiva & Decocción & Oral y Tópico & Caliente \\
\hline & & & & Corteza & Fiebre & $\begin{array}{c}\text { Antipirética o } \\
\text { febrífuga }\end{array}$ & Decocción & Oral & Caliente \\
\hline & & & & Corteza & Dolor & $\begin{array}{l}\text { Analgésico o } \\
\text { calmante }\end{array}$ & Decocción & Oral & Caliente \\
\hline \multirow{5}{*}{ 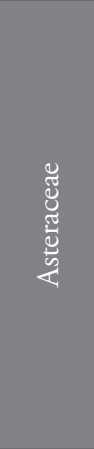 } & \multirow[t]{2}{*}{ Ambrosia } & & \multirow[t]{2}{*}{ Altamisa } & Hojas & Cólicos & $\begin{array}{l}\text { Antidisme- } \\
\text { norréicos o } \\
\text { emenagoga }\end{array}$ & Decocción & Oral y Baños & Caliente \\
\hline & & & & Hojas & Parto & Parturiente & Decocción & Oral y Baños & Caliente \\
\hline & Emilia & $\begin{array}{c}\text { Emilia } \\
\text { sonchifolia }\end{array}$ & $\begin{array}{l}\text { Amansa } \\
\text { caballo }\end{array}$ & Hojas & Brujería & $\begin{array}{l}\text { Mágico- } \\
\text { religiosa }\end{array}$ & Cruda & No aplica & Fría \\
\hline & Gossypium & & Julio & Hojas & Hemorragias & $\begin{array}{l}\text { Vulneraria, } \\
\text { citofiláctico }\end{array}$ & Chapeo & Tópica & Caliente \\
\hline & Tagetes & & $\begin{array}{c}\text { Rosa } \\
\text { amarilla }\end{array}$ & $\begin{array}{l}\text { Planta } \\
\text { entera }\end{array}$ & $\begin{array}{c}\text { Protección a } \\
\text { los niños }\end{array}$ & $\begin{array}{l}\text { Mágico- } \\
\text { religiosa }\end{array}$ & Decocción & Baños & Caliente \\
\hline 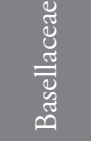 & Basella & & Espinaca & Hojas & Anemia & $\begin{array}{l}\text { Hematopo- } \\
\text { yética }\end{array}$ & Decocción & Oral & Fría \\
\hline
\end{tabular}




\begin{tabular}{|c|c|c|c|c|c|c|c|c|c|}
\hline Familia & Género & Especie & $\begin{array}{c}\text { Nombre } \\
\text { Vernáculo } \\
\end{array}$ & $\begin{array}{l}\text { Parte } \\
\text { usada } \\
\end{array}$ & Uso popular & $\begin{array}{c}\text { Propiedad } \\
\text { medicinal } \\
\end{array}$ & Preparación & Administración & $\begin{array}{c}\text { Categoría } \\
\text { térmica } \\
\end{array}$ \\
\hline \multirow{12}{*}{ 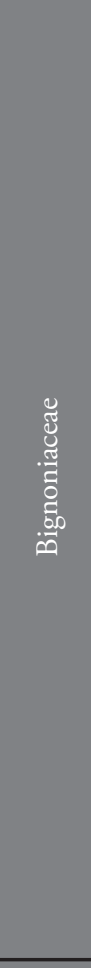 } & \multirow{6}{*}{ Macfadyena } & & \multirow{6}{*}{$\begin{array}{l}\text { Bejuco } \\
\text { manito }\end{array}$} & Raíz & Impotencia & Afrodisiaco & Decocción & Oral & Fría \\
\hline & & & & Raíz & Diabetes & $\begin{array}{l}\text { Hipogluce- } \\
\text { miante }\end{array}$ & Decocción & Oral & Fría \\
\hline & & & & Raíz & Dolor & $\begin{array}{c}\text { Analgésico o } \\
\text { calmante }\end{array}$ & Decocción & Oral & Fría \\
\hline & & & & Raíz & Gripa & $\begin{array}{c}\text { Antiséptica y } \\
\text { Antipirética o } \\
\text { febrífuga }\end{array}$ & Decocción & Oral & Fría \\
\hline & & & & Raíz & Paludismo & Antiparasitaria & Decocción & Oral & Fría \\
\hline & & & & Raíz & Frio & $\begin{array}{l}\text { Mágico- } \\
\text { religiosa }\end{array}$ & Decocción & Oral & Fría \\
\hline & Sesamum & $\begin{array}{c}\text { Sesamum } \\
\text { oriaclarartale }\end{array}$ & $\begin{array}{l}\text { Cedro, } \\
\text { roble }\end{array}$ & $\begin{array}{l}\text { Corteza } \\
\text { y Hojas }\end{array}$ & Diabetes & $\begin{array}{l}\text { Hipogluce- } \\
\text { miante }\end{array}$ & Decocción & Oral & Fría \\
\hline & Tabebuia & $\begin{array}{c}\text { Tabebuia } \\
\text { serratiflora }\end{array}$ & Roble & Hojas & Suerte & $\begin{array}{l}\text { Mágico- } \\
\text { religiosa }\end{array}$ & Decocción & Oral & $\begin{array}{c}\text { Fría y } \\
\text { Caliente }\end{array}$ \\
\hline & \multirow{4}{*}{ Crescentia } & \multirow{4}{*}{$\begin{array}{l}\text { Crescentia } \\
\text { cujete }\end{array}$} & \multirow{4}{*}{ Totumo } & \multirow{4}{*}{$\begin{array}{l}\text { Fruto, } \\
\text { flor, } \\
\text { pulpa y } \\
\text { ramas }\end{array}$} & Gripa & $\begin{array}{l}\text { Antiséptica y } \\
\text { Antipirética o } \\
\text { febrífuga }\end{array}$ & Decocción & Oral & Fría \\
\hline & & & & & Post-parto & Emenagogo & Decocción & Oral & Fría \\
\hline & & & & & Hongos & Antifúngica & Decocción & Oral & Fría \\
\hline & & & & & Brujería & $\begin{array}{l}\text { Mágico- } \\
\text { religiosa }\end{array}$ & Decocción & Oral & Fría \\
\hline \multirow{2}{*}{ 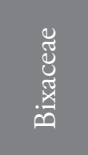 } & \multirow{2}{*}{ Bixa } & \multirow[t]{2}{*}{$\begin{array}{c}\text { Bixa } \\
\text { orellana }\end{array}$} & \multirow{2}{*}{ Achote } & \multirow{2}{*}{$\begin{array}{l}\text { Hojas y } \\
\text { Semilla }\end{array}$} & Quemadura & Vulneraria & Decocción & Tópica & Caliente \\
\hline & & & & & Purgante & Tenífuga & Decocción & Oral & Caliente \\
\hline \multirow{4}{*}{ 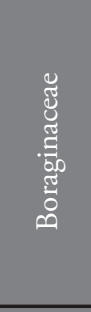 } & Cordia & $\begin{array}{c}\text { Cordia } \\
\text { sebestina }\end{array}$ & Topacio & Flor & Brujería & $\begin{array}{l}\text { Mágico- } \\
\text { religiosa }\end{array}$ & Cruda & No aplica & Caliente \\
\hline & \multirow{3}{*}{ Heliotropium } & \multirow{3}{*}{$\begin{array}{c}\text { Heliotropium } \\
\text { indicum }\end{array}$} & \multirow{3}{*}{$\begin{array}{l}\text { Verbena } \\
\text { blanca }\end{array}$} & \multirow{3}{*}{$\begin{array}{l}\text { Planta } \\
\text { entera }\end{array}$} & Gripa & $\begin{array}{l}\text { Antiséptica y } \\
\text { Antipirética }\end{array}$ & Decocción & Baños & Fría \\
\hline & & & & & Parto & Parturiente & Decocción & Baños & Fría \\
\hline & & & & & Lombrices & $\begin{array}{l}\text { Tenífuga o } \\
\text { Vermífuga } \\
\end{array}$ & Decocción & Oral & Fría \\
\hline \multirow{2}{*}{ 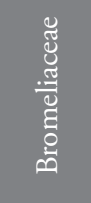 } & \multirow{2}{*}{ Tillandsia } & & \multirow{2}{*}{ Gallito } & \multirow{2}{*}{$\begin{array}{l}\text { Planta } \\
\text { entera }\end{array}$} & Mal de ojo & $\begin{array}{l}\text { Mágico- } \\
\text { religiosa }\end{array}$ & Decocción & Baños & Fría \\
\hline & & & & & Dolor & $\begin{array}{l}\text { Analgésico o } \\
\text { calmante }\end{array}$ & Decocción & Baños & Fría \\
\hline \multirow{2}{*}{ 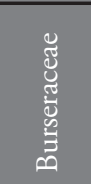 } & \multirow{2}{*}{ Bursera } & \multirow{2}{*}{$\begin{array}{l}\text { Bursera } \\
\text { simaruba }\end{array}$} & \multirow{2}{*}{$\begin{array}{c}\text { Indio } \\
\text { desnudo }\end{array}$} & \multirow{2}{*}{$\begin{array}{c}\text { Hojas y } \\
\text { Tallo }\end{array}$} & $\begin{array}{l}\text { Mordedura } \\
\text { de serpiente }\end{array}$ & Antiofídica & Decocción & Oral & Fría \\
\hline & & & & & Piel & Vulneraria & Decocción & Tópica & Fría \\
\hline 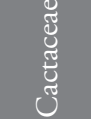 & Ripsalis & & $\begin{array}{l}\text { Mierda de } \\
\text { pajarito }\end{array}$ & $\begin{array}{l}\text { Planta } \\
\text { entera }\end{array}$ & Energizante & Asténica & Decocción & Baños & Fría \\
\hline
\end{tabular}




\begin{tabular}{|c|c|c|c|c|c|c|c|c|c|}
\hline Familia & Género & Especie & $\begin{array}{l}\text { Nombre } \\
\text { Vernáculo }\end{array}$ & $\begin{array}{l}\text { Parte } \\
\text { usada }\end{array}$ & Uso popular & $\begin{array}{l}\text { Propiedad } \\
\text { medicinal }\end{array}$ & Preparación & Administración & $\begin{array}{l}\text { Categoría } \\
\text { térmica }\end{array}$ \\
\hline \multirow{6}{*}{ 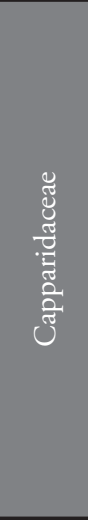 } & Crateva & $\begin{array}{l}\text { Crateva } \\
\text { tapia }\end{array}$ & $\begin{array}{l}\text { Naranjito } \\
\text { o guamo }\end{array}$ & Hojas & Brujería & $\begin{array}{l}\text { Mágico- } \\
\text { religiosa }\end{array}$ & Decocción & Cataplasma & Caliente \\
\hline & \multirow{4}{*}{$\begin{array}{l}\text { Capparidas- } \\
\text { trum }\end{array}$} & & \multirow{2}{*}{ Negrito } & \multirow{2}{*}{ Hojas } & $\begin{array}{c}\text { Dolor de } \\
\text { cabeza }\end{array}$ & $\begin{array}{l}\text { Analgésico o } \\
\text { calmante }\end{array}$ & Decocción & Baños & $\begin{array}{l}\text { Caliente } \\
\text { y fría }\end{array}$ \\
\hline & & & & & Brujería & $\begin{array}{l}\text { Mágico- } \\
\text { religiosa }\end{array}$ & Decocción & No aplica & $\begin{array}{c}\text { Caliente } \\
\text { y fría }\end{array}$ \\
\hline & & & \multirow{2}{*}{ Sincogollo } & \multirow{2}{*}{$\begin{array}{l}\text { Planta } \\
\text { entera }\end{array}$} & Brujería & $\begin{array}{l}\text { Mágico- } \\
\text { religiosa }\end{array}$ & Decocción & Baños & Fría \\
\hline & & & & & $\begin{array}{l}\text { Mordedura } \\
\text { de serpiente }\end{array}$ & Antiofídica & Decocción & Baños & Fría \\
\hline & Capparis & & Olivo & Hojas & Brujería & $\begin{array}{l}\text { Mágico- } \\
\text { religiosa }\end{array}$ & Chapeo & Oral & Caliente \\
\hline & \multirow{3}{*}{ Carica } & \multirow{3}{*}{$\begin{array}{l}\text { Carica } \\
\text { papaya }\end{array}$} & \multirow{3}{*}{ Papaya } & Resina & Estreńimiento & Digestiva & Cruda & Oral & Fría \\
\hline 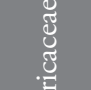 & & & & $\begin{array}{c}\text { Fruto y } \\
\text { resina }\end{array}$ & Celulitis & $\begin{array}{c}\text { Dérmica } \\
\text { (Anticelulítica) }\end{array}$ & Cruda & Tópica & Fría \\
\hline$\tilde{J}$ & & & & $\begin{array}{c}\text { Fruto y } \\
\text { resina }\end{array}$ & $\begin{array}{l}\text { Cáncer } \\
\text { (seno) }\end{array}$ & Anticancerígena & Cruda & Tópica & Fría \\
\hline$\underset{\widetilde{J}}{\mathscr{J}}$ & \multirow[b]{2}{*}{ Chenopodium } & \multirow{2}{*}{$\begin{array}{l}\text { Chenopodium } \\
\text { ambrosioides }\end{array}$} & \multirow[b]{2}{*}{ Paico } & Hojas & Purgante & Tenífuga & Decocción & Oral & Caliente \\
\hline $\begin{array}{l}\text { ஃ } \\
\frac{0}{0} \\
\frac{\Xi}{0}\end{array}$ & & & & Hojas & Suerte & $\begin{array}{l}\text { Mágico- } \\
\text { religiosa }\end{array}$ & Decocción & Oral & Caliente \\
\hline $\begin{array}{l}\frac{\mathscr{J}}{\tilde{J}} \\
\frac{\pi}{\tilde{J}} \\
\frac{3}{3} \\
\end{array}$ & Mammea & $\begin{array}{l}\text { Mammea } \\
\text { americana }\end{array}$ & Mamey & Corteza & $\begin{array}{l}\text { Mordedura } \\
\text { de serpiente }\end{array}$ & Antiofídica & Chapeo & Oral & Caliente \\
\hline \multirow{4}{*}{ 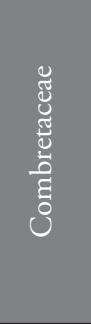 } & \multirow{3}{*}{ Terminalia } & \multirow{3}{*}{$\begin{array}{l}\text { Terminalia } \\
\text { catappa }\end{array}$} & \multirow{3}{*}{ Almendro } & Hojas & Desinflamar & Emoliente & Decocción & Tópica & Fría \\
\hline & & & & Hojas & Heridas & Vulneraria & Decocción & Tópica & Fría \\
\hline & & & & Hojas & Quemaduras & Vulneraria & Decocción & Tópica & Fría \\
\hline & Combretum & $\begin{array}{c}\text { Combretum } \\
\text { indicum }\end{array}$ & Victoriosa & Tallo & Brujería & $\begin{array}{l}\text { Mágico- } \\
\text { religiosa }\end{array}$ & No aplica & No aplica & Fría \\
\hline 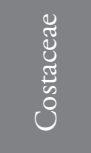 & Costus & & $\begin{array}{c}\text { Caña } \\
\text { de mico } \\
\text { blanca/ } \\
\text { morada }\end{array}$ & Tallo & Riñones & Diuréticas & $\begin{array}{c}\text { Cruda / } \\
\text { Decocción }\end{array}$ & Oral & Fría \\
\hline 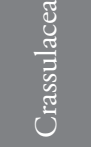 & Kalanchoe & $\begin{array}{c}\text { Kalanchoe } \\
\text { pinnata }\end{array}$ & $\begin{array}{c}\text { Hoja del } \\
\text { diablo }\end{array}$ & Hoja & Brujería & $\begin{array}{l}\text { Mágico- } \\
\text { religiosa }\end{array}$ & Cruda & No aplica & Caliente \\
\hline
\end{tabular}




\begin{tabular}{|c|c|c|c|c|c|c|c|c|c|}
\hline Familia & Género & Especie & $\begin{array}{l}\text { Nombre } \\
\text { Vernáculo }\end{array}$ & $\begin{array}{l}\text { Parte } \\
\text { usada }\end{array}$ & Uso popular & $\begin{array}{l}\text { Propiedad } \\
\text { medicinal }\end{array}$ & Preparación & Administración & $\begin{array}{c}\text { Categoría } \\
\text { térmica }\end{array}$ \\
\hline \multirow{5}{*}{ 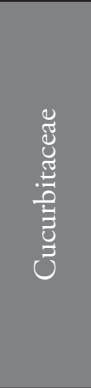 } & \multirow{5}{*}{ Momordica } & \multirow{5}{*}{$\begin{array}{l}\text { Momordica } \\
\text { charantia }\end{array}$} & \multirow{5}{*}{ Balsamina } & \multirow{5}{*}{$\begin{array}{l}\text { Planta } \\
\text { entera }\end{array}$} & Fiebre & $\begin{array}{c}\text { Antipirética o } \\
\text { febrífuga }\end{array}$ & Chapeo & Cutánea & Caliente \\
\hline & & & & & Parásitos & $\begin{array}{l}\text { Tenífuga o } \\
\text { Vermífuga }\end{array}$ & Chapeo & Cutánea & Caliente \\
\hline & & & & & Estreñimiento & Digestiva & Chapeo & Cutánea & Caliente \\
\hline & & & & & Paludismo & Antiparasitaria & Chapeo & Cutánea & Caliente \\
\hline & & & & & Dolor & $\begin{array}{c}\text { Analgésico o } \\
\text { calmante }\end{array}$ & Chapeo & Cutánea & Caliente \\
\hline \multirow{2}{*}{ 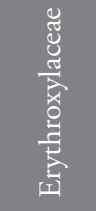 } & \multirow{2}{*}{ Erythroxylum } & & \multirow{2}{*}{ Coca } & \multirow{2}{*}{ Hojas } & Brujería & $\begin{array}{l}\text { Mágico- } \\
\text { religiosa }\end{array}$ & Chapeo & Oral y Baños & Caliente \\
\hline & & & & & $\begin{array}{l}\text { Mordedura } \\
\text { de serpiente }\end{array}$ & Antiofídica & Chapeo & Oral y Baños & Caliente \\
\hline \multirow{13}{*}{ 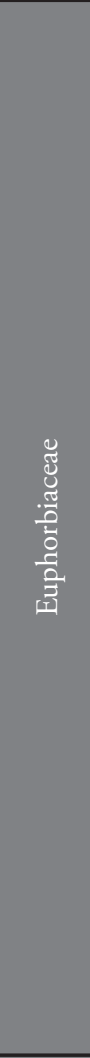 } & Cnidoscolus & $\begin{array}{l}\text { Cnidoscolus } \\
\text { urens }\end{array}$ & Pringamoza & Flor & $\begin{array}{l}\text { Mordedura } \\
\text { de serpiente }\end{array}$ & Antiofídica & Decocción & Baños & Caliente \\
\hline & \multirow[t]{2}{*}{ Croton } & & \multirow[t]{2}{*}{ Salvia } & \multirow[t]{2}{*}{ Hojas } & Gripa & $\begin{array}{l}\text { Antiséptica y } \\
\text { Antipirética o } \\
\text { febrífuga }\end{array}$ & Decocción & Oral & Caliente \\
\hline & & & & & Impotencia & Afrodisiaco & Decocción & Oral & Caliente \\
\hline & Hura & $\begin{array}{c}\text { Hura } \\
\text { crepitans }\end{array}$ & $\begin{array}{l}\text { Ceiba de } \\
\text { leche }\end{array}$ & Resina & $\begin{array}{l}\text { Extraer } \\
\text { dientes }\end{array}$ & $\begin{array}{l}\text { Analgésico o } \\
\text { calmante }\end{array}$ & Cruda & Tópica & Caliente \\
\hline & \multirow{5}{*}{ Jatropha } & & \multirow{5}{*}{$\begin{array}{l}\text { Coquito } \\
\text { blanco }\end{array}$} & \multirow{5}{*}{ Hojas } & Riñones & Diurética & Chapeo & Oral & Fría \\
\hline & & & & & $\begin{array}{c}\text { Dolor del } \\
\text { cuerpo }\end{array}$ & $\begin{array}{l}\text { Analgésico o } \\
\text { calmante }\end{array}$ & Chapeo & Oral & Fría \\
\hline & & & & & $\begin{array}{c}\text { Irritación } \\
\text { vaginal }\end{array}$ & Anti-irritante & Chapeo & Baños & Fría \\
\hline & & & & & Colesterol & Anti-colesterol & Chapeo & Oral & Fría \\
\hline & & & & & Riñones & Diuréticas & Chapeo & Oral & Fría \\
\hline & \multirow{2}{*}{ Phyllanthus } & \multirow{2}{*}{$\begin{array}{l}\text { Phyllanthus } \\
\text { niruri }\end{array}$} & \multirow{2}{*}{$\begin{array}{c}\text { Flor } \\
\text { escondida }\end{array}$} & \multirow{2}{*}{$\begin{array}{l}\text { Hojas } \\
\text { y } \\
\text { Flores }\end{array}$} & Diabetes & $\begin{array}{c}\text { Hipogluce- } \\
\text { miante }\end{array}$ & Decocción & Oral & Fría \\
\hline & & & & & Brujería & $\begin{array}{l}\text { Mágico- } \\
\text { religiosa }\end{array}$ & Decocción & Oral & Fría \\
\hline & Ricinus & $\begin{array}{l}\text { Ricinus } \\
\text { communis }\end{array}$ & Higuereta & Hojas & Inflamación & $\begin{array}{l}\text { Antiflogístico } \\
\text { Emoliente }\end{array}$ & Decocción & Tópica & Fría \\
\hline & Pedilanthus & $\begin{array}{l}\text { Pedilanthus } \\
\text { tithymaloides }\end{array}$ & Pitamorrial & Resina & $\begin{array}{l}\text { Dolor de } \\
\text { oído }\end{array}$ & Ótico & Cruda & Tópica & Fría \\
\hline \multirow{3}{*}{ 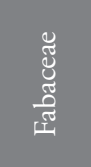 } & \multirow{3}{*}{ Acacia } & \multirow{3}{*}{$\begin{array}{l}\text { Acacia } \\
\text { collinsii }\end{array}$} & \multirow{3}{*}{ Macho solo } & \multirow{3}{*}{ Raíz } & Impotencia & Afrodisiaco & Decocción & Oral & Caliente \\
\hline & & & & & Circulación & Diurético & Decocción & Oral & Caliente \\
\hline & & & & & Digestión & Digestiva & Decocción & Oral & Caliente \\
\hline
\end{tabular}




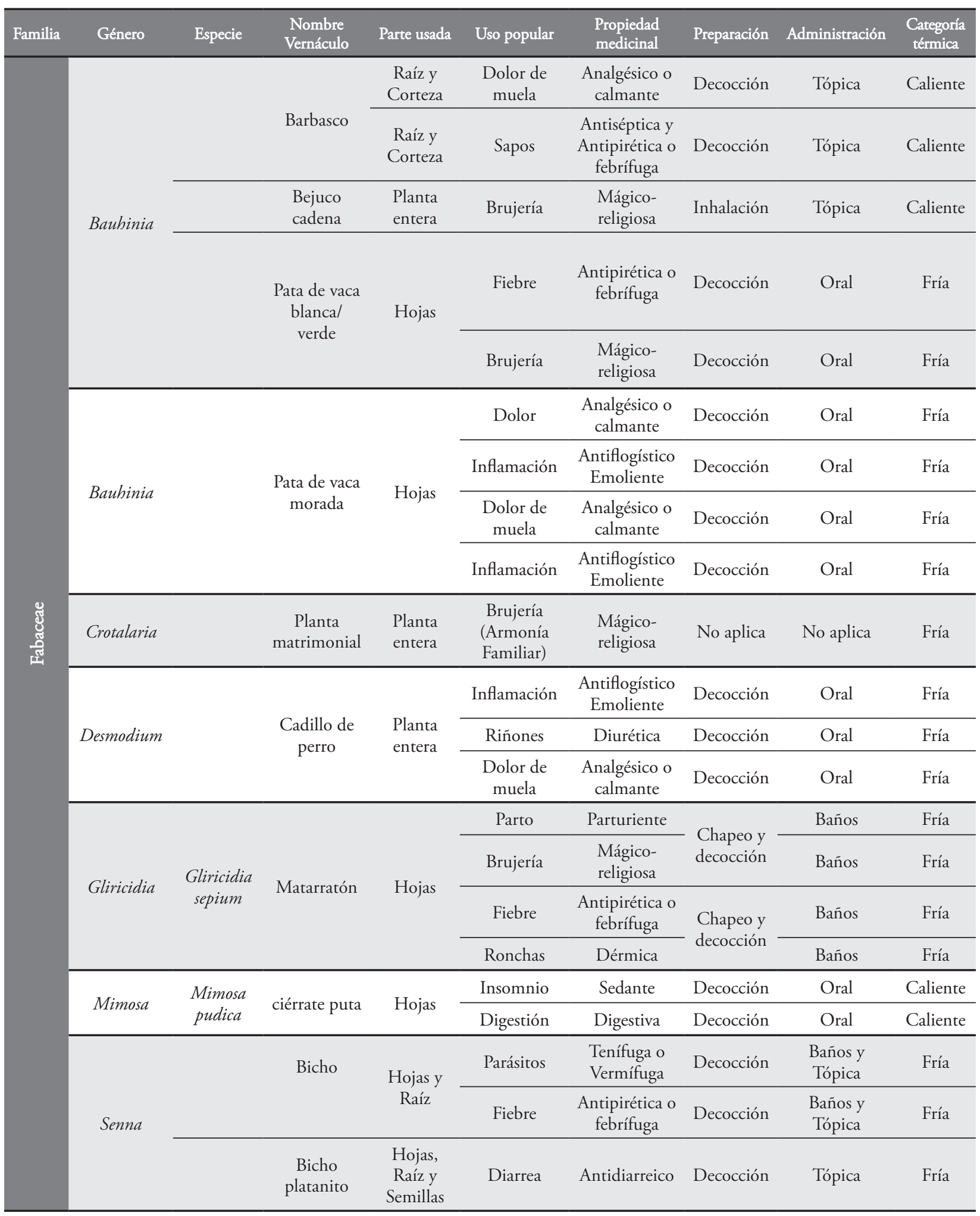




\begin{tabular}{|c|c|c|c|c|c|c|c|c|c|}
\hline Familia & Género & Especie & $\begin{array}{l}\text { Nombre } \\
\text { Vernáculo }\end{array}$ & $\begin{array}{l}\text { Parte } \\
\text { usada }\end{array}$ & Uso popular & $\begin{array}{l}\text { Propiedad } \\
\text { medicinal }\end{array}$ & Preparación & Administración & $\begin{array}{l}\text { Categoría } \\
\text { térmica }\end{array}$ \\
\hline \multirow{5}{*}{ 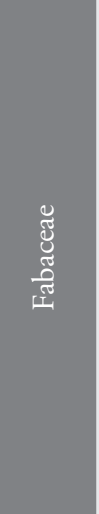 } & \multirow{5}{*}{ Senna } & & $\begin{array}{l}\text { Bicho } \\
\text { platanito }\end{array}$ & $\begin{array}{l}\text { Hojas, } \\
\text { Raíz y } \\
\text { Semillas }\end{array}$ & $\begin{array}{l}\text { Dolor de } \\
\text { estómago }\end{array}$ & $\begin{array}{l}\text { Antidiarreico, } \\
\text { Analgésico o } \\
\text { calmante }\end{array}$ & Decocción & Tópica & Fría \\
\hline & & & \multirow{2}{*}{ Cigarrón } & \multirow{2}{*}{$\begin{array}{l}\text { Planta } \\
\text { entera }\end{array}$} & $\begin{array}{c}\text { Fiebre } \\
\text { Amarilla }\end{array}$ & $\begin{array}{c}\text { Antipirética } \\
\text { o febrífuga }\end{array}$ & Decocción & Baños & Fría \\
\hline & & & & & Dolor & $\begin{array}{l}\text { Analgésico o } \\
\text { calmante }\end{array}$ & Decocción & Baños & Fría \\
\hline & & & \multirow[b]{2}{*}{ Majagua } & \multirow[b]{2}{*}{ Hojas } & Purgante & $\begin{array}{l}\text { Tenífuga o } \\
\text { Vermífuga }\end{array}$ & Decocción & Oral & Fría \\
\hline & & & & & $\begin{array}{l}\text { Mordedura } \\
\text { de serpiente } \\
\text { (Desinflamar) }\end{array}$ & Emoliente & Decocción & Oral & Fría \\
\hline \multirow{2}{*}{ 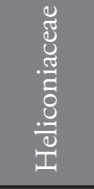 } & \multirow{2}{*}{ Heliconia } & & \multirow{2}{*}{$\begin{array}{l}\text { Lengua de } \\
\text { vaca }\end{array}$} & \multirow{2}{*}{ Flor } & Riñón & Diuréticas & Decocción & Tópica & Fría \\
\hline & & & & & Cáncer & $\begin{array}{c}\text { Anticancerí- } \\
\text { gena }\end{array}$ & Decocción & Tópica & Fría \\
\hline \multirow{8}{*}{ 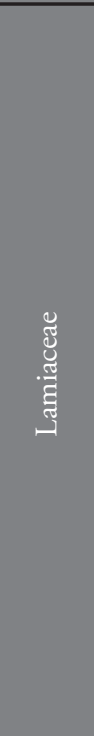 } & \multirow{3}{*}{ Aegiphila } & & \multirow{3}{*}{$\begin{array}{l}\text { Juan de la } \\
\text { verdad }\end{array}$} & \multirow{3}{*}{ Hojas } & $\begin{array}{l}\text { Dolor de } \\
\text { cabeza }\end{array}$ & $\begin{array}{l}\text { Analgésico o } \\
\text { calmante }\end{array}$ & $\begin{array}{l}\text { Decocción } \\
\text { y Chapeo }\end{array}$ & $\begin{array}{l}\text { Baños y } \\
\text { Tópica }\end{array}$ & Caliente \\
\hline & & & & & Fiebre & $\begin{array}{c}\text { Antipirética } \\
\text { o febrífuga }\end{array}$ & $\begin{array}{l}\text { Decocción } \\
\text { y Chapeo }\end{array}$ & $\begin{array}{l}\text { Baños y } \\
\text { Tópica }\end{array}$ & Caliente \\
\hline & & & & & Brujería & $\begin{array}{l}\text { Mágico- } \\
\text { religiosa }\end{array}$ & $\begin{array}{l}\text { Decocción } \\
\text { y Chapeo }\end{array}$ & $\begin{array}{l}\text { Baños y } \\
\text { Tópica }\end{array}$ & Caliente \\
\hline & Hyptis & & Pelotica & Semillas & Cataratas & $\begin{array}{l}\text { Oftálmica } \\
\text { (Colirio) }\end{array}$ & Cruda & Tópica & Fría \\
\hline & \multirow{4}{*}{ Ocimum } & & Albahaca & $\begin{array}{l}\text { Hojas y } \\
\text { Ramas }\end{array}$ & Fiebre & $\begin{array}{l}\text { Antipirética } \\
\text { o febrífuga }\end{array}$ & Cruda & Tópica & Fría \\
\hline & & & & & $\begin{array}{l}\text { Brujería } \\
\text { (Buena } \\
\text { suerte) }\end{array}$ & $\begin{array}{l}\text { Mágico-reli- } \\
\text { giosa }\end{array}$ & Decocción & Baños & Caliente \\
\hline & & & Cotorrera & Hojas & Cataratas & $\begin{array}{l}\text { Oftálmica } \\
\text { (Colirio) }\end{array}$ & Decocción & Tópica & Caliente \\
\hline & & & & & Piel & Dérmica & Cruda & Baños & Caliente \\
\hline \multirow{5}{*}{ 胥 } & \multirow[t]{2}{*}{ Ocimum } & & \multirow{2}{*}{$\begin{array}{l}\text { Toronjil de } \\
\text { casa }\end{array}$} & \multirow[b]{2}{*}{ Hojas } & Nervios & Hipotensiva & Decocción & Oral & Caliente \\
\hline & & & & & Cataratas & $\begin{array}{c}\text { Oftálmica } \\
\text { (Colirio) }\end{array}$ & Decocción & Tópica & Caliente \\
\hline & \multirow{3}{*}{ Plectranthus } & & \multirow{3}{*}{$\begin{array}{l}\text { Orégano } \\
\text { orejón }\end{array}$} & \multirow{3}{*}{ Hojas } & Dolor de oído & Ótico & Decocción & Tópica & Fría \\
\hline & & & & & Diabetes & $\begin{array}{l}\text { Hipogluce- } \\
\text { miante }\end{array}$ & Decocción & Oral & Fría \\
\hline & & & & & Gripa & $\begin{array}{l}\text { Antiséptica y } \\
\text { Antipirética } \\
\text { o febrífuga }\end{array}$ & Decocción & Tópica & Fría \\
\hline 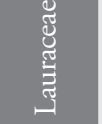 & Persea & $\begin{array}{c}\text { Persea } \\
\text { americana }\end{array}$ & Aguacate & Hojas & $\begin{array}{c}\text { Brujería } \\
\text { (Buena Suerte) }\end{array}$ & $\begin{array}{l}\text { Mágico- } \\
\text { religiosa }\end{array}$ & Decocción & Oral & Caliente \\
\hline
\end{tabular}




\begin{tabular}{|c|c|c|c|c|c|c|c|c|c|}
\hline Familia & Género & Especie & $\begin{array}{l}\text { Nombre } \\
\text { Vernáculo }\end{array}$ & $\begin{array}{l}\text { Parte } \\
\text { usada }\end{array}$ & Uso popular & $\begin{array}{l}\text { Propiedad } \\
\text { medicinal }\end{array}$ & Preparación & Administración & $\begin{array}{l}\text { Categoría } \\
\text { térmica }\end{array}$ \\
\hline \multirow{2}{*}{ 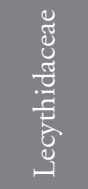 } & Gustavia & & Membrillo & $\begin{array}{l}\text { Planta } \\
\text { entera }\end{array}$ & Brujería & $\begin{array}{l}\text { Mágico- } \\
\text { religiosos }\end{array}$ & Cruda & No Aplica & Fría \\
\hline & Lecythis & & $\begin{array}{l}\text { Olla de } \\
\text { mono }\end{array}$ & Flor & Ulcera & Antiácido & Decocción & Tópica & Fría \\
\hline \multirow{2}{*}{ 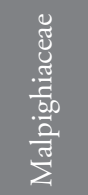 } & \multirow{2}{*}{ Stigmaphyllon } & & \multirow{2}{*}{$\begin{array}{l}\text { Bejuco de } \\
\text { San Juan }\end{array}$} & \multirow{2}{*}{ Hojas } & Dolor & $\begin{array}{l}\text { Analgésico o } \\
\text { calmante }\end{array}$ & Decocción & Baños & Fría \\
\hline & & & & & Cólicos & $\begin{array}{l}\text { Antidisme- } \\
\text { norréicos }\end{array}$ & Decocción & Baños & Fría \\
\hline \multirow{10}{*}{ 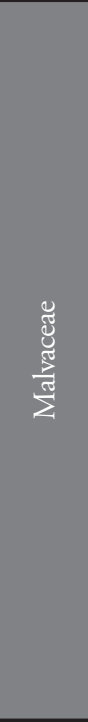 } & Corchorus & & $\begin{array}{c}\text { Escobilla de } \\
\text { flor }\end{array}$ & $\begin{array}{l}\text { Planta } \\
\text { entera }\end{array}$ & Fecundidad & Fertilizantes & Decocción & Oral & Fría \\
\hline & Gossypium & & Algodón & Hojas & Brujería & $\begin{array}{l}\text { Mágico- } \\
\text { religiosa }\end{array}$ & Decocción & Tópica & Fría \\
\hline & \multirow[t]{2}{*}{ Guazuma } & \multirow{2}{*}{$\begin{array}{l}\text { Guazuma } \\
\text { ulmifolia }\end{array}$} & \multirow[t]{2}{*}{ Guasimo } & \multirow[t]{2}{*}{ Corteza } & Inflamación & $\begin{array}{l}\text { Antiflogísti- } \\
\text { co Emoliente }\end{array}$ & Decocción & Oral & Fría \\
\hline & & & & & Heridas & Vulneraria & Decocción & Oral & Fría \\
\hline & Hibiscus rosa & $\begin{array}{c}\text { Hibiscus } \\
\text { rosa-sinensis }\end{array}$ & $\begin{array}{l}\text { Flor de } \\
\text { muerto }\end{array}$ & Flor & $\begin{array}{l}\text { Cáncer (Evita } \\
\text { la aparición) }\end{array}$ & $\begin{array}{l}\text { Mágico- } \\
\text { religiosa }\end{array}$ & Cruda & Oral & Fría \\
\hline & \multirow{2}{*}{ Malva } & & \multirow{2}{*}{ Malva } & \multirow{2}{*}{ Hojas } & Riñones & Diuréticas & Decocción & Oral & Fría \\
\hline & & & & & Parto & Parturiente & Decocción & Oral & Fría \\
\hline & \multirow[t]{2}{*}{ Psuedobombax } & \multirow{2}{*}{$\begin{array}{c}\text { Psuedobombax } \\
\text { septenatum }\end{array}$} & \multirow{2}{*}{$\begin{array}{l}\text { Majagua } \\
\text { gallina }\end{array}$} & \multirow[t]{2}{*}{ Fruto } & Dolor & $\begin{array}{l}\text { Analgésico o } \\
\text { calmante }\end{array}$ & Decocción & Vaporización & Fría \\
\hline & & & & & Riñones & Diuréticas & Decocción & Vaporización & Fría \\
\hline & Sterculia & $\begin{array}{l}\text { Sterculia } \\
\text { apetala }\end{array}$ & Camajón & Semillas & Purgante & $\begin{array}{l}\text { Tenífuga o } \\
\text { Vermífuga }\end{array}$ & Decocción & Oral & Caliente \\
\hline \multirow{3}{*}{ 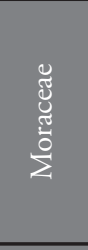 } & \multirow{2}{*}{ Dorstenia } & & \multirow{2}{*}{$\begin{array}{l}\text { Cresta de } \\
\text { Gallo }\end{array}$} & \multirow{2}{*}{$\begin{array}{l}\text { Planta } \\
\text { entera } \\
\text { y Raíz } \\
\end{array}$} & Impotencia & Afrodisiaco & Decocción & Oral & Fría \\
\hline & & & & & Riñones & Diurética & Decocción & Oral & Fría \\
\hline & Ficus & & Uvero & $\begin{array}{l}\text { Planta } \\
\text { entera } \\
\text { y Raíz } \\
\end{array}$ & Brujería & $\begin{array}{l}\text { Mágico- } \\
\text { religiosa }\end{array}$ & No aplica & No aplica & Caliente \\
\hline 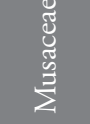 & Musa & & Plátano & $\begin{array}{l}\text { Cascara } \\
\text { y Resina }\end{array}$ & $\begin{array}{l}\text { Anticoncep- } \\
\text { tivo }\end{array}$ & $\begin{array}{l}\text { Anticoncep- } \\
\text { tivo }\end{array}$ & $\begin{array}{c}\text { Cruda y } \\
\text { Decocción }\end{array}$ & Oral & Fría \\
\hline \multirow{4}{*}{ 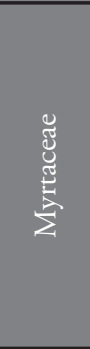 } & \multirow{3}{*}{ Psidium } & \multirow{3}{*}{$\begin{array}{l}\text { Psidium } \\
\text { guajava }\end{array}$} & \multirow{3}{*}{ Guayaba } & \multirow{3}{*}{$\begin{array}{l}\text { Hojas } \\
\text { y fruto }\end{array}$} & Diarrea & Antidiarreico & Decocción & Oral & Caliente \\
\hline & & & & & Fiebre & $\begin{array}{c}\text { Antipirética } \\
\text { o febrífuga }\end{array}$ & Decocción & Oral & Caliente \\
\hline & & & & & Colesterol & $\begin{array}{c}\text { Anti- } \\
\text { colesterol }\end{array}$ & Decocción & Oral & Caliente \\
\hline & Gossypium & & $\begin{array}{l}\text { Guayaba } \\
\text { ácida }\end{array}$ & Hojas & Gripa & $\begin{array}{c}\text { Antiséptica y } \\
\text { Antipirética } \\
\text { o febrífuga }\end{array}$ & Decocción & Baños & Fría \\
\hline 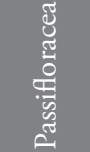 & Passiflora & $\begin{array}{l}\text { Passiflora } \\
\text { foetida }\end{array}$ & Cinco llagas & $\begin{array}{l}\text { Planta } \\
\text { entera }\end{array}$ & Riñones & Diurética & Decocción & Oral & Fría \\
\hline
\end{tabular}




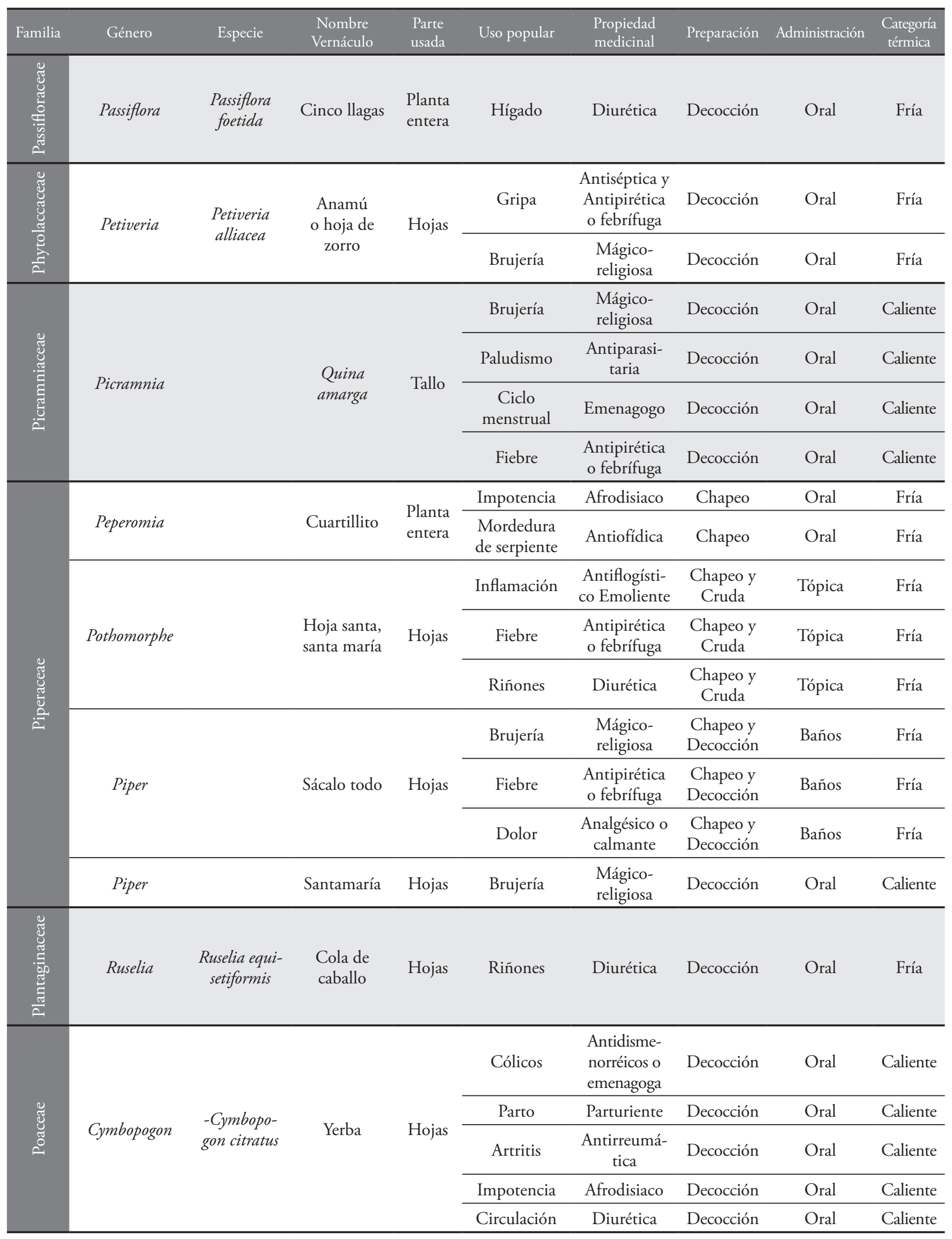




\begin{tabular}{|c|c|c|c|c|c|c|c|c|c|}
\hline Familia & Género & Especie & $\begin{array}{l}\text { Nombre } \\
\text { Vernáculo } \\
\end{array}$ & $\begin{array}{l}\text { Parte } \\
\text { usada }\end{array}$ & Uso popular & $\begin{array}{c}\text { Propiedad } \\
\text { medicinal } \\
\end{array}$ & Preparación & Administración & $\begin{array}{c}\text { Categoría } \\
\text { térmica } \\
\end{array}$ \\
\hline 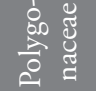 & Triplaris & & Varasanta & Hojas & Dolor & $\begin{array}{l}\text { Analgésico o } \\
\text { calmante }\end{array}$ & Decocción & No Aplica & Fría \\
\hline 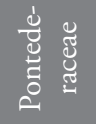 & Eichhornia & $\begin{array}{l}\text { Eichhor- } \\
\text { nia azurea }\end{array}$ & $\begin{array}{l}\text { Caminante } \\
\text { de agua, } \\
\text { Tapón }\end{array}$ & $\begin{array}{l}\text { Planta } \\
\text { entera }\end{array}$ & $\begin{array}{c}\text { Brujería } \\
\text { (Protección) }\end{array}$ & $\begin{array}{l}\text { Mágico- } \\
\text { religiosa }\end{array}$ & Cruda & No Aplica & Fría \\
\hline 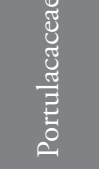 & Portulaca & $\begin{array}{c}\text { Portulaca } \\
\text { oleraceae }\end{array}$ & Verdolaga & $\begin{array}{l}\text { Planta } \\
\text { entera }\end{array}$ & $\begin{array}{l}\text { Debilidad en } \\
\text { la sangre }\end{array}$ & Depuración & Decocción & Oral & Fría \\
\hline \multirow{5}{*}{ 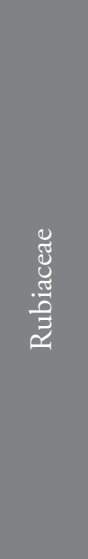 } & \multirow{3}{*}{ Randia } & & \multirow{3}{*}{$\begin{array}{l}\text { Chocolatillo. } \\
\text { Espuela de } \\
\text { indio }\end{array}$} & \multirow{3}{*}{ Hojas } & Gripa & $\begin{array}{c}\text { Antiséptica y } \\
\text { Antipirética o } \\
\text { febrífuga }\end{array}$ & Decocción & Oral & Fría \\
\hline & & & & & $\begin{array}{l}\text { Mordedura } \\
\text { de serpiente }\end{array}$ & Antiofídica & Decocción & Oral & Fría \\
\hline & & & & & Menopausia & $\begin{array}{l}\text { Antidismeno- } \\
\text { rréicos }\end{array}$ & Decocción & Oral & Fría \\
\hline & Randia & & $\begin{array}{l}\text { Jefe del } \\
\text { diablo }\end{array}$ & $\begin{array}{l}\text { Planta } \\
\text { entera }\end{array}$ & Brujería & $\begin{array}{l}\text { Mágico- } \\
\text { religiosa }\end{array}$ & Cruda & No Aplica & Caliente \\
\hline & Morinda & $\begin{array}{l}\text { Morinda } \\
\text { citrifolia }\end{array}$ & Noni & Hojas & Osteoporosis & Calcificante & Decocción & Oral & Fría \\
\hline \multirow{14}{*}{ 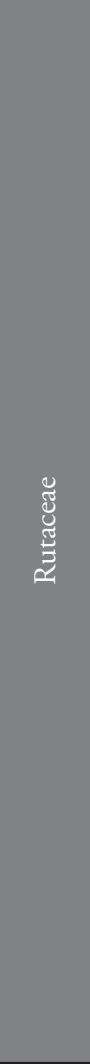 } & Murraya & $\begin{array}{c}\text { Murraya } \\
\text { exotica }\end{array}$ & $\begin{array}{l}\text { Azahar de } \\
\text { la India }\end{array}$ & Hojas & Dolor & $\begin{array}{l}\text { Analgésico o cal- } \\
\text { mante, Sedante }\end{array}$ & Chapeo & Tópica & Fría \\
\hline & Citrus & Citrus & Limón & Fruto & Hemorragias & $\begin{array}{l}\text { Vulneraria, } \\
\text { citofiláctico }\end{array}$ & Cruda & Oral y Tópico & Fría \\
\hline & & & & & Colesterol & Anti-colesterol & Cruda & Oral y Tópico & Fría \\
\hline & \multirow{6}{*}{ Citrus } & \multirow{6}{*}{$\begin{array}{l}\text { Citrus } \\
\text { medica }\end{array}$} & \multirow{6}{*}{ Limón } & \multirow{6}{*}{ Fruto } & Circulación & Diurético & Cruda & Oral y Tópico & Fría \\
\hline & & & & & Gripa & $\begin{array}{l}\text { Antiséptica, } \\
\text { Antipirética }\end{array}$ & Cruda & Oral y Tópico & Fría \\
\hline & & & & & Diarrea & Antidiarreico & Cruda & Oral y Tópico & Fría \\
\hline & & & & & Ojos & Oftálmica & Cruda & Oral y Tópico & Fría \\
\hline & & & & & Heridas & Vulneraria & Cruda & Oral y Tópico & Fría \\
\hline & & & & & Desinflamar & Emoliente & Cruda & Oral y Tópico & Fría \\
\hline & Citrus & $\begin{array}{l}\text { Citrus } \\
\text { limonum }\end{array}$ & $\begin{array}{l}\text { Limón } \\
\text { mandarino }\end{array}$ & Fruto & Gripa & $\begin{array}{c}\text { Antiséptica y } \\
\text { Antipirética o } \\
\text { febrífuga }\end{array}$ & Cruda & Oral y Tópico & Fría \\
\hline & \multirow{3}{*}{ Citrus } & & \multirow{3}{*}{$\begin{array}{l}\text { Naranja } \\
\text { dulce }\end{array}$} & \multirow{3}{*}{ Fruto } & Gripa & $\begin{array}{l}\text { Antiséptica, } \\
\text { Antipirética }\end{array}$ & Decocción & Oral & $\begin{array}{c}\text { Caliente } \\
\text { y Fría }\end{array}$ \\
\hline & & & & & Purgante & $\begin{array}{l}\text { Tenífuga o } \\
\text { Vermífuga }\end{array}$ & Decocción & Oral & $\begin{array}{c}\text { Caliente } \\
\text { y Fría }\end{array}$ \\
\hline & & & & & Cólicos & $\begin{array}{l}\text { Antidismeno- } \\
\text { rréicos o } \\
\text { emenagoga }\end{array}$ & Decocción & Oral & $\begin{array}{l}\text { Caliente } \\
\text { y Fría }\end{array}$ \\
\hline & Citrus & & $\begin{array}{c}\text { Naranjo } \\
\text { agrio }\end{array}$ & Hojas & Diarrea & Anti-Diarreico & Decocción & Oral & Caliente \\
\hline
\end{tabular}




\begin{tabular}{|c|c|c|c|c|c|c|c|c|c|}
\hline Familia & Género & Especie & $\begin{array}{c}\text { Nombre } \\
\text { Vernáculo } \\
\end{array}$ & $\begin{array}{l}\text { Parte } \\
\text { usada } \\
\end{array}$ & Uso popular & $\begin{array}{l}\text { Propiedad } \\
\text { medicinal } \\
\end{array}$ & Preparación & Administración & $\begin{array}{c}\text { Categoría } \\
\text { térmica } \\
\end{array}$ \\
\hline 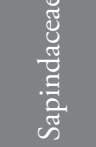 & Dilodendron & & $\begin{array}{l}\text { Tapangoté } \\
\text { de monte }\end{array}$ & Fruto & Brujería & $\begin{array}{l}\text { Mágico- } \\
\text { religiosa }\end{array}$ & Cruda & No Aplica & Fría \\
\hline \multirow{7}{*}{ 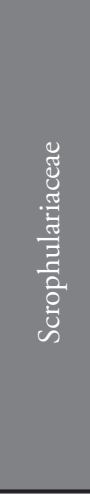 } & \multirow{4}{*}{ Scoparia } & \multirow{4}{*}{$\begin{array}{c}\text { Scoparia } \\
\text { dulcis }\end{array}$} & \multirow{4}{*}{$\begin{array}{l}\text { Escobilla } \\
\text { menuda, } \\
\text { Pimientica }\end{array}$} & \multirow{4}{*}{$\begin{array}{l}\text { Planta } \\
\text { entera }\end{array}$} & Diarrea & Antidiarreico & Decocción & Bańos & Fría \\
\hline & & & & & Parto & Parturiente & Decocción & Baños & Fría \\
\hline & & & & & Vomitar & Anti-emética & Decocción & Baños & Fría \\
\hline & & & & & $\begin{array}{c}\text { Mordedura de } \\
\text { serpiente }\end{array}$ & Antiofídica & Decocción & Baños & Fría \\
\hline & \multirow{3}{*}{ Scoparia } & \multirow{3}{*}{$\begin{array}{l}\text { Scoparia } \\
\text { dulcis }\end{array}$} & \multirow{3}{*}{$\begin{array}{l}\text { Escobilla } \\
\text { menuda, } \\
\text { Pimientica }\end{array}$} & \multirow{3}{*}{$\begin{array}{l}\text { Planta } \\
\text { entera }\end{array}$} & Purgante & $\begin{array}{l}\text { Tenífuga o } \\
\text { Vermífuga }\end{array}$ & Decocción & Baños & Fría \\
\hline & & & & & Fiebre & $\begin{array}{c}\text { Antipirética } \\
\text { o febrífuga }\end{array}$ & Decocción & Baños & Fría \\
\hline & & & & & Brujería & $\begin{array}{l}\text { Mágico- } \\
\text { religiosa }\end{array}$ & Decocción & Baños & Fría \\
\hline \multirow{7}{*}{ 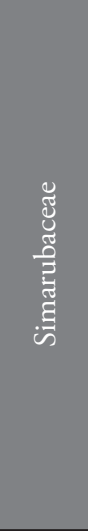 } & \multirow{7}{*}{ Quassia } & \multirow{7}{*}{$\begin{array}{l}\text { Quassia } \\
\text { amara }\end{array}$} & \multirow{7}{*}{$\begin{array}{l}\text { Cruceto } \\
\text { morado }\end{array}$} & \multirow{7}{*}{ Tallo } & Vomitar & Emética & Cruda & Oral & Caliente \\
\hline & & & & & $\begin{array}{c}\text { Mordedura de } \\
\text { serpiente }\end{array}$ & Antiofídica & Cruda & Oral & Caliente \\
\hline & & & & & Dolor & $\begin{array}{c}\text { Analgésico o } \\
\text { calmante }\end{array}$ & Cruda & Oral & Caliente \\
\hline & & & & & Brujería & $\begin{array}{l}\text { Mágico-reli- } \\
\text { giosa }\end{array}$ & Cruda & Oral & Caliente \\
\hline & & & & & Paludismo & $\begin{array}{c}\text { Antiparasi- } \\
\text { taria } \\
\end{array}$ & Cruda & Oral & Caliente \\
\hline & & & & & Gripa & $\begin{array}{l}\text { Antiséptica, } \\
\text { Antipirética }\end{array}$ & Cruda & Oral & Caliente \\
\hline & & & & & Impotencia & Afrodisiaco & Cruda & Oral & Caliente \\
\hline \multirow{7}{*}{ 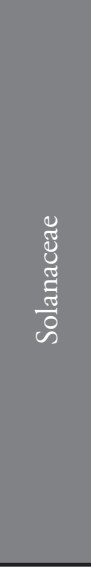 } & \multirow{3}{*}{ Capsicum } & & Ají & Fruto & Brujería & $\begin{array}{l}\text { Mágico- } \\
\text { religiosa }\end{array}$ & Decocción & Oral & Caliente \\
\hline & & & \multirow{2}{*}{$\begin{array}{l}\text { Ají guau } \\
\text { guau }\end{array}$} & \multirow{2}{*}{ Raíz } & $\begin{array}{l}\text { Dolor de } \\
\text { estómago }\end{array}$ & $\begin{array}{l}\text { Analgésico o } \\
\text { calmante }\end{array}$ & Chapeo & Oral & Caliente \\
\hline & & & & & Brujería & $\begin{array}{l}\text { Mágico- } \\
\text { religiosa } \\
\end{array}$ & Chapeo & Oral & Caliente \\
\hline & \multirow[t]{3}{*}{ Physalis } & & $\begin{array}{l}\text { Bolsa de } \\
\text { monte }\end{array}$ & Hojas & $\begin{array}{c}\text { Dérmica } \\
\text { (Ronchas) }\end{array}$ & $\begin{array}{c}\text { Antiflogístico } \\
\text { Emoliente }\end{array}$ & Chapeo & Bańos & Fría \\
\hline & & & \multirow[t]{2}{*}{ Toporopo } & \multirow[t]{2}{*}{ Fruto } & Diabetes & $\begin{array}{l}\text { Hipogluce- } \\
\text { miante }\end{array}$ & Chapeo & Oral & Fría \\
\hline & & & & & Conjuntivitis & Oftálmica & Chapeo & Tópica & Fría \\
\hline & Solanum & $\begin{array}{c}\text { Solanum } \\
\text { nigrum }\end{array}$ & Yerbamora & Hojas & Brujería & $\begin{array}{l}\text { Mágico- } \\
\text { religiosa }\end{array}$ & Decocción & Baños & Fría \\
\hline \multirow{2}{*}{ 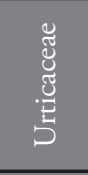 } & Urera & & $\begin{array}{c}\text { Pringamoza } \\
\text { ordinaria }\end{array}$ & Hojas & $\begin{array}{c}\text { Mordedura de } \\
\text { serpiente }\end{array}$ & Antiofídica & Decocción & Baños & Fría \\
\hline & Pilea & & $\begin{array}{c}\text { Sangrina } \\
\text { maligna }\end{array}$ & Hojas & $\begin{array}{c}\text { Retraso } \\
\text { (Menstruación) }\end{array}$ & Emenagogo & Decocción & Oral & Fría \\
\hline 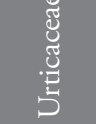 & Cecropia & $\begin{array}{c}\text { Cecropia } \\
\text { sciadophylla }\end{array}$ & Yarumo & $\begin{array}{l}\text { Planta } \\
\text { Entera }\end{array}$ & Gripa & $\begin{array}{l}\text { Antiséptica y } \\
\text { Antipirética }\end{array}$ & Decocción & Baños & Fría \\
\hline
\end{tabular}




\begin{tabular}{|c|c|c|c|c|c|c|c|c|c|}
\hline Familia & Género & Especie & $\begin{array}{l}\text { Nombre } \\
\text { Vernáculo }\end{array}$ & $\begin{array}{l}\text { Parte } \\
\text { usada }\end{array}$ & Uso popular & $\begin{array}{l}\text { Propiedad } \\
\text { medicinal }\end{array}$ & Preparación & Administración & $\begin{array}{l}\text { Categoría } \\
\text { térmica }\end{array}$ \\
\hline \multirow{5}{*}{ 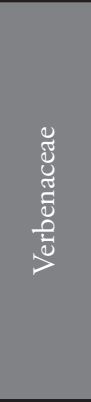 } & \multirow{2}{*}{ Priva } & \multirow{2}{*}{$\begin{array}{c}\text { Priva } \\
\text { lappulacea }\end{array}$} & \multirow{2}{*}{$\begin{array}{l}\text { Cadillo de } \\
\text { bolsa }\end{array}$} & \multirow{2}{*}{$\begin{array}{l}\text { Planta } \\
\text { Entera }\end{array}$} & Brujería & $\begin{array}{l}\text { Mágico- } \\
\text { religiosa }\end{array}$ & Decocción & Baños & Fría \\
\hline & & & & & $\begin{array}{c}\text { Dolor de } \\
\text { muela }\end{array}$ & $\begin{array}{c}\text { Analgésico o } \\
\text { calmante }\end{array}$ & Decocción & Baños & Fría \\
\hline & \multirow{3}{*}{ Lippia } & & \multirow{3}{*}{ Oreganito } & \multirow{3}{*}{$\begin{array}{l}\text { Planta } \\
\text { Entera }\end{array}$} & Dolor de oído & Ótico & Decocción & Baños & Fría \\
\hline & & & & & $\begin{array}{c}\text { Dolor de } \\
\text { cabeza }\end{array}$ & $\begin{array}{c}\text { Analgésico o } \\
\text { calmante }\end{array}$ & Decocción & Baños & Fría \\
\hline & & & & & Brujería & $\begin{array}{l}\text { Mágico- } \\
\text { religiosa }\end{array}$ & Decocción & Baños & Fría \\
\hline \multirow{5}{*}{ 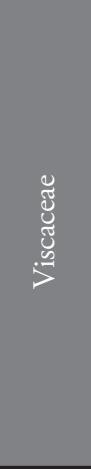 } & \multirow{5}{*}{ Phoradendron } & & \multirow{5}{*}{$\begin{array}{l}\text { Cagalita, } \\
\text { cagada de } \\
\text { pájaro, } \\
\text { planta } \\
\text { voladora }\end{array}$} & \multirow{5}{*}{ Hojas } & Diabetes & $\begin{array}{l}\text { Hipogluce- } \\
\text { miante }\end{array}$ & Decocción & Oral & Fría \\
\hline & & & & & $\begin{array}{l}\text { Circulación } \\
\text { (Trombosis) }\end{array}$ & Diurética & Decocción & Oral & Fría \\
\hline & & & & & Inflamación & $\begin{array}{l}\text { Antiflogístico } \\
\text { Emoliente }\end{array}$ & Decocción & Oral & Fría \\
\hline & & & & & Riñones & Diuréticas & Decocción & Oral & Fría \\
\hline & & & & & Brujería & $\begin{array}{l}\text { Mágico- } \\
\text { religiosa }\end{array}$ & Decocción & Oral & Fría \\
\hline 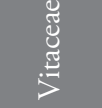 & Cissus & & Zarzaparrilla & $\begin{array}{l}\text { Planta } \\
\text { Entera }\end{array}$ & Riñones & Diurética & Decocción & Oral & Fría \\
\hline \multirow{3}{*}{ 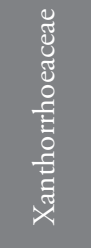 } & \multirow{3}{*}{ Aloe } & \multirow{3}{*}{ Aloe vera } & \multirow{3}{*}{ Sábila } & \multirow{2}{*}{ Resina } & Quemadura & Vulneraria & Cruda & Tópica & Caliente \\
\hline & & & & & Inflamación & Antiflogístico & Cruda & Tópica & Caliente \\
\hline & & & & $\begin{array}{l}\text { Planta } \\
\text { entera }\end{array}$ & $\begin{array}{l}\text { Brujería } \\
\text { (Suerte) }\end{array}$ & $\begin{array}{l}\text { Mágico- } \\
\text { religiosa }\end{array}$ & Cruda & Tópica & Caliente \\
\hline \multirow{3}{*}{ 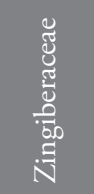 } & \multirow{3}{*}{ Alpinia } & & \multirow{3}{*}{$\begin{array}{c}\text { Ajinjible } \\
\text { macho o } \\
\text { Matandrea }\end{array}$} & \multirow{3}{*}{$\begin{array}{l}\text { Hojas } \\
\text { y Tallo }\end{array}$} & Fiebre & Antipirética & Decocción & Oral & Fría \\
\hline & & & & & Dolor & Analgésico & Decocción & Oral & Fría \\
\hline & & & & & Brujería & $\begin{array}{l}\text { Mágico- } \\
\text { religiosa }\end{array}$ & Decocción & Oral & Fría \\
\hline
\end{tabular}

\section{Discusión}

\section{Análisis floristico}

En la Figura 1 se expone que, de las 58 familias encontradas en este estudio, las más representativas son la Fabaceae (13 plantas); Euforbiaceae (7 plantas);
Malvaceae (7 plantas). El hecho que tanto estudios realizados de plantas medicinales en el Caribe (42); (21) y el Amazonas reporten las familias Euforbiaceae y Fabaceae (43-46) como familias vegetales representativas a nivel medicinal en el Amazonas, sirve como un indicativo de su importancia en este valor de uso y en su diversidad en el país. 


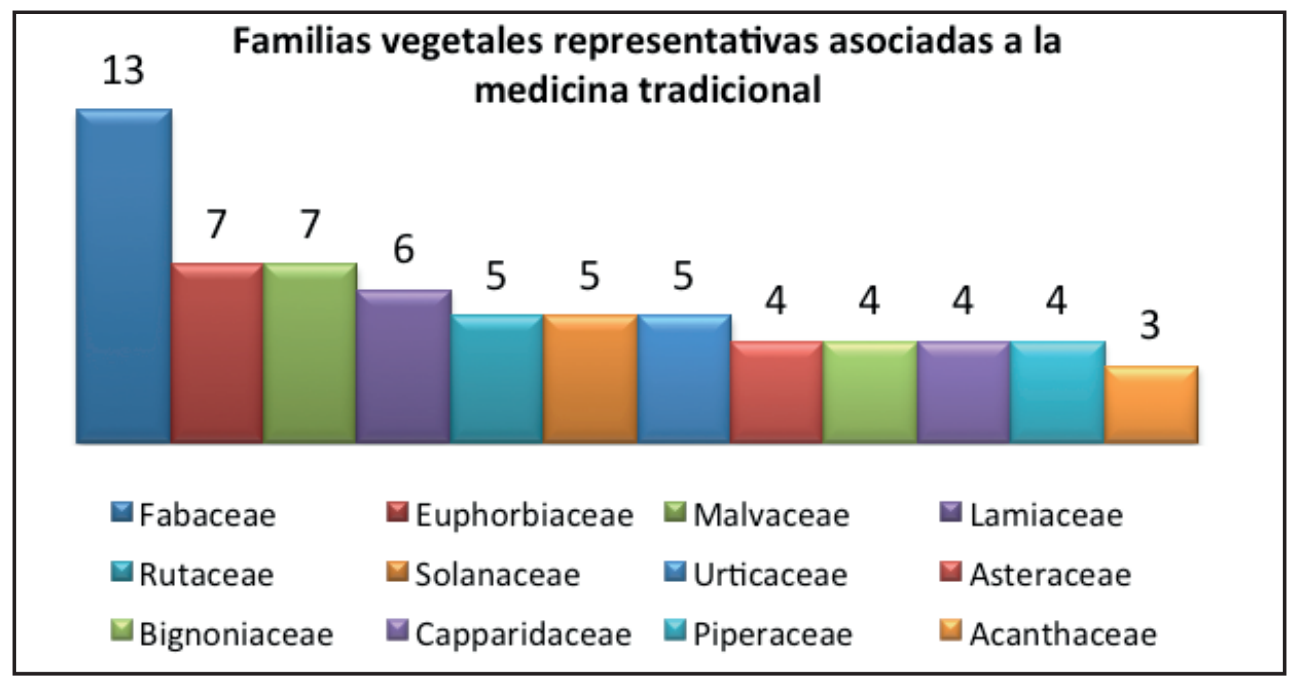

Figura 1. Géneros reportados de familias vegetales asociadas a la medicina tradicional

En este orden de ideas al analizar la relación de las familias botánicas Fabaceae, Malvaceae y Eforbiaceae con estudios realizados en África occidental (ver Figura 2), se encuentra que estas familias también son las de mayor valor de uso medicinal en diferentes reportes (47-65).

Es de resaltar que al comparar los reportes de la familia Boraginaceae, el género Cordia tuvo coincidencias de uso medicinal entre los estudios de Aces (47), Honeychurch (52), Abiiw (55),
Roig (57), Martin et al., (63). Por otro lado, al comparar los reportes de la familia Fabaceae se encontró que esta familia tenía el mayor número de reportes en 19 de los 21 estudios analizados, existiendo concurrencia del mismo uso en los géneros Bauhnia, Acacia, Crotalaria y Demodium. Finalmente, al comparar el análisis de uso de la familia Euforbiaceae, se encontró coincidencias en los reportes de uso en el género crotón y en la especie Ricinus comunis, la cual tenía el mismo reporte de uso medicinal en los estudios analizados.

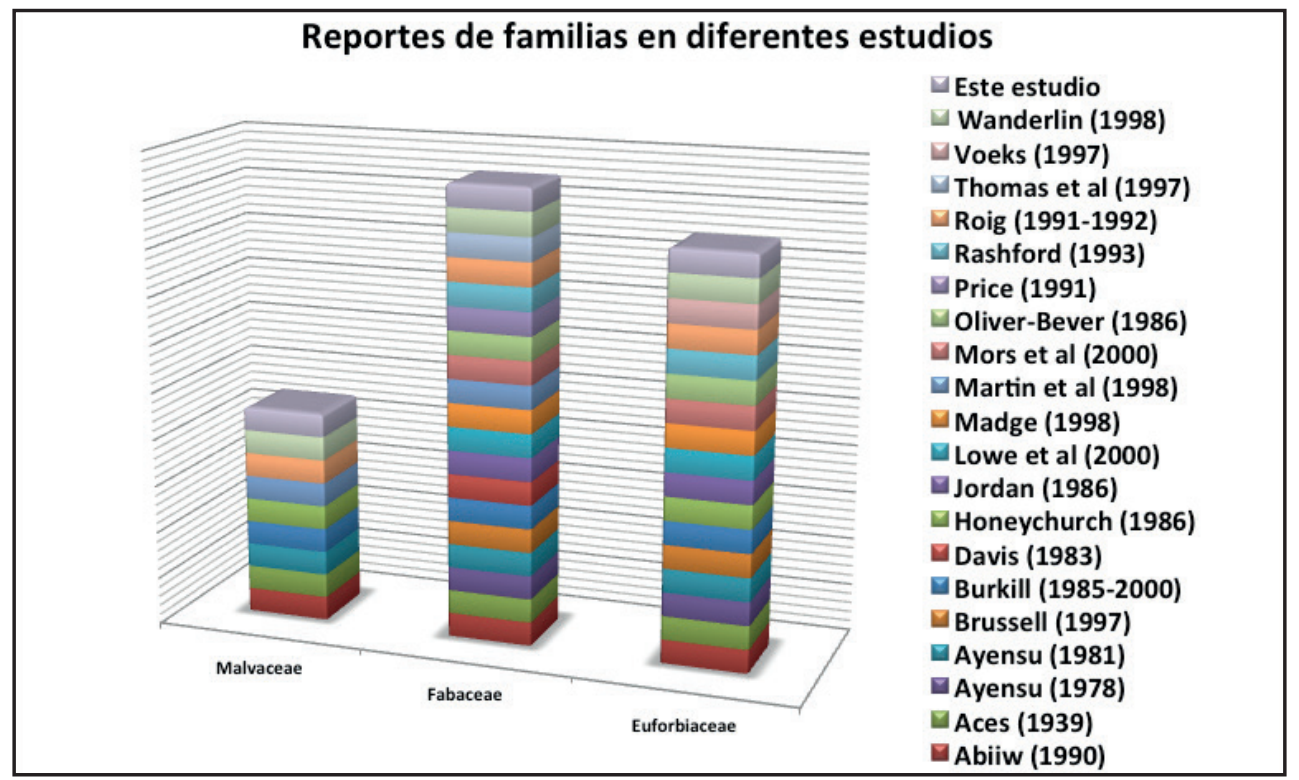

Figura 2. Familias taxonómicas representativas con valor de uso medicinal entre este estudio y los realizados en África. 
De acuerdo a Carney (66) los reportes similares en el uso de las familias taxonómicas entre África y América se deben a la experimentación de los esclavizados con plantas pertenecientes a las mismas familias botánicas que conocían desde sus países de origen por sus propiedades curativas, lo que generó un sincretismo de conocimientos tradicionales entre los indígenas y los africanos.

\section{Criterios taxonómicos vegetales de los sabedores medicinales}

Debido a que los saberes botánicos y medicinales africanos fueron parte de los saberes de la Nueva Granada, se encuentran documentos sobre el tema que datan de 1664. En estos se detallan las acusaciones y "juicios" llevadas a cabo a los Mohanes o Maestros de hechiceros, en los que ellos describieron el origen de sus saberes relacionados con el mundo vegetal y con la enfermedad como un aprendizaje ancestral y ético (el ritual de iniciación se desarrollaba en un río donde un espíritu los atraía al centro; si ellos lograban salir, eran dignos de recibir el conocimiento y se comprometían a no afectar el clima, los cultivos ni a las personas) que tuvieron en África (67).

Dentro de los criterios taxonómicos descritos sobresale la identificación por el olor para categorizar la virtud de la planta; así como la clasificación térmica propia de las tradiciones africanas Adja-Évhé de plantas calificadas de "calientes" (dodzo) o "frescas" (fafa) (68). Criterios que como lo demuestran los estudios en comunidades afrodescendientes continuaron siendo trasmitidos de los africanos a sus hijos criollos y mulatos (69), y cuya categorización en San Basilio de Palenque tiene los siguientes parámetros:

- Plantas calientes o fuertes (masculinas). Son plantas cuya proliferación se encuentra asociada al verano, son utilizadas para tratar enfermedades que se piensa son causadas o empeoradas por el "frío". Tienen generalmente un sabor amargo o picante, se encuentran generalmente en lomerias, expuestas al sol y al viento, alejadas de los cuerpos de agua. A estas se asocian la cura de pasmos o la sangre que no corre bien por el cuerpo (cólicos menstruales, partos prolongados, artritis, impotencia, circulación), paludismo, dolor de muela, dolor de cabeza, resfriados, protección de la casa, mal aire (se asocia con un espíritu y el sereno), diarrea.

- Plantas frías o frescas (femeninas). Son plantas cuya proliferación se encuentra asociada al invierno. Son utilizadas para tratar enfermedades que se piensa son causadas o empeoradas por el "calor". Tienen generalmente un sabor ácido o sin sabor, se encuentran generalmente en sitios sombríos, poco expuestos al viento y están cercanas a cuerpos de agua ya sea de los lomeríos o las zonas bajas. A estas se relacionan la cura de problemas asociadas con la inflamación (cieguita o conjuntivitis, fogaje o hígado, riñones o irritación, piel, sistema digestivo), mal de ojo o afición, sapos o lesiones blanquecinas en la boca, emociones, estreñimiento, parásitos de la cabeza, debilidad en la sangre o problemas en las primeras etapas del embarazo, purgante o laxante.

La Figura 3 expone una clasificación de plantas frías y calientes que se basa en las cualidades específicas de la planta y no necesariamente en el clima del punto geográfico donde se encuentran. En este sentido autores como Nates, Cerón \& Hernández (70) hablan del concepto de calidad del remedio, que está determinado por las plantas que se combinan, la forma de preparación (de acuerdo con los autores, la jerarquización de calor en las plantas es dada por la preparación, siendo una planta más caliente si se cocina que si se da en infusión o se da sin preparación) y el estado de descomposición de las plantas.

Pese a lo anterior, autores como Losonzcy (19) establecen que la ubicación de la vegetación cerca de cuerpos de agua o su color blanco, son características que se piensa, transmiten a las plantas un carácter "frío" o femenino, mientras que la flora de lugares más secos y de color rojo o violáceo es "caliente" o masculina. Asimismo, la clasificación entre plantas masculinas y femeninas, se puede establecer por el sabor de las plantas como es el caso de las plantas calientes o masculinas cuyo sabor se asocia con el sabor amargo (18). 


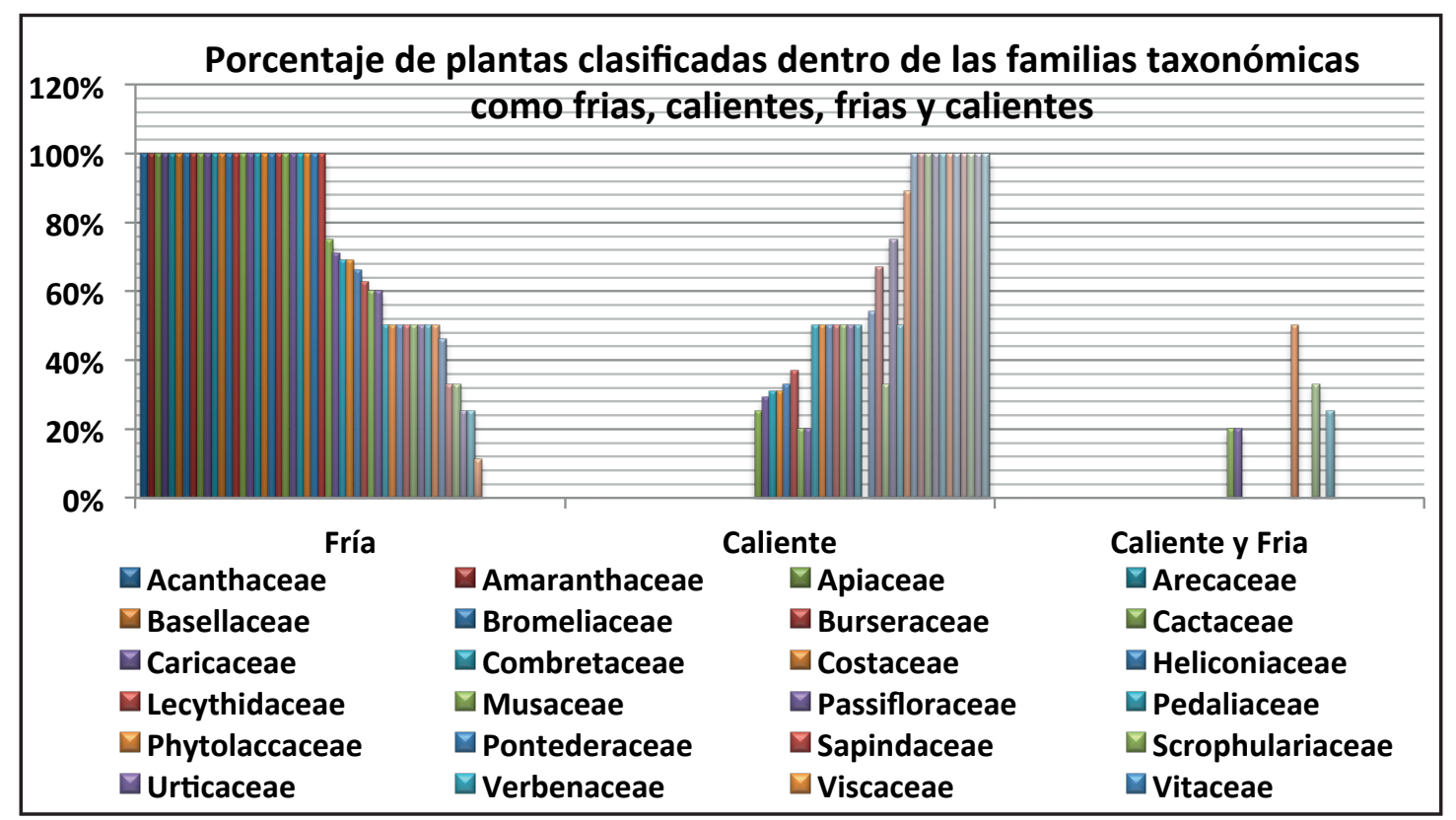

Figura 3. Categorías térmicas por familias

En este sentido diferentes autores como Velásquez (17), Valencia (31), Suárez (71) y Zuluaga (16) resaltan que la lógica afrocolombiana medicinal proviene de un mundo inmaterial que se expresa a través de la cosmovisión, en donde las deidades del mundo de las aguas son predominante femeninas (Madreagua, Sirena, Catalina Loango) leyenda de Palenque que establece el rapto de ella por un chimbumbe o espíritu subacuático, pese a esto ella sigue regresando a la comunidad a los funerales y luego desaparece a media noche (32). Mientras que las deidades asociadas al bosque y al fuego son predominantemente masculinas (el Diablo, el Mohán y el Duende).

Asimismo, es de destacar que la Figura 3 expone una predominancia de plantas frías o femeninas; lo que amplía la discusión sobre la complejidad social de la mujer afro en Colombia, hacia unos imaginarios míticos que pueden estar determinando el cumplimiento de sus roles específicos dentro de la sociedad.

\section{Análisis de uso}

\section{Relación ser humano-territorio-uso medicinal}

Al analizar la posología de los tratamientos se estableció que los momentos de recolección no se relacionan con la clasificación frío-caliente, de esta manera se reportan plantas frías y calientes cuya preparación se asocia a la madrugada, tarde o noche. Cabe resaltar que en el estudio de Velásquez (17) realizado en el Pacífico chocoano y vallecaucano, el tratamiento de las enfermedades estaba determinado por los momentos del día, es así que los tratamientos de enfermedades relacionadas con el calor se hacían en la noche y las relacionadas con el frío en el día.

La Figura 4 expone el valor de uso medicinal mágico-espiritual para gran parte de las familias botánicas, esto es debido a que la medicina tradicional Palenquera tiene prácticas rituales propias que descienden del legado africano mágicoreligioso Bantú, lo que expone un conglomerado 
de conocimientos y técnicas que dan respuesta a múltiples enfermedades ocasionados por la envidia de otras personas (según Escalante (72) se cree que la envidia de otros afecta el comportamiento y la suerte del afectado), espíritus ancestrales (se considera que la presencia de los muertos en los rituales puede servir bien sea para ayudar a curar o morir), zánganos (brujos, de acuerdo con Escalante (72), toman forma de animales terrestres como caballos, burros o cerdos y pueden afectar el bienestar de las personas "atropellando o embotellando su sombra"), bularías (brujas que vuelan. Según Escalante (72), toman forma de animales de aire como patos, pavos o gallinas, por lo que pueden volar en la noche para extraer por hendiduras de los techos la sangre de los nińos) y hechiceras (brujas que no vuelan, De acuerdo con Escalante (72), estas mujeres pisan la sombra de las personas causándoles enfermedades o la muerte); sobresaliendo entidades como "afición o mal de ojo", "conjuelo" (ratón que ingresa por los genitales de la mujer cuanto esta se bańa en el arroyo, provocando abortos y el labio leporino en los infantes), "el ma" (ata a los bebes y puede llegar afectarlos hasta el mes y medio de vida.)

Para protegerse contra la hechicería se usa el Nkisi (espíritu ancestral en la forma de un objeto que ayuda a quien lo porta, talismanes hechos de semillas o hierbas como la cabalonga, el colicencio, o la cruceta. Se cree que protege el alma humana y ayuda al enfermo en su padecimiento), collares de huesos de gallinazo y cruces de malambito cortadas los viernes de cuaresma y atadas por el centro con un bejuco para proteger las casas $(32,72)$; así como oraciones a la virgen del Carmen (72) y Santa Bárbara quien es una deidad protectora de rayos y tormentas relacionada con el dios de la virilidad Changó, dueño de los tambores, símbolo del rayo y del color rojo (32).

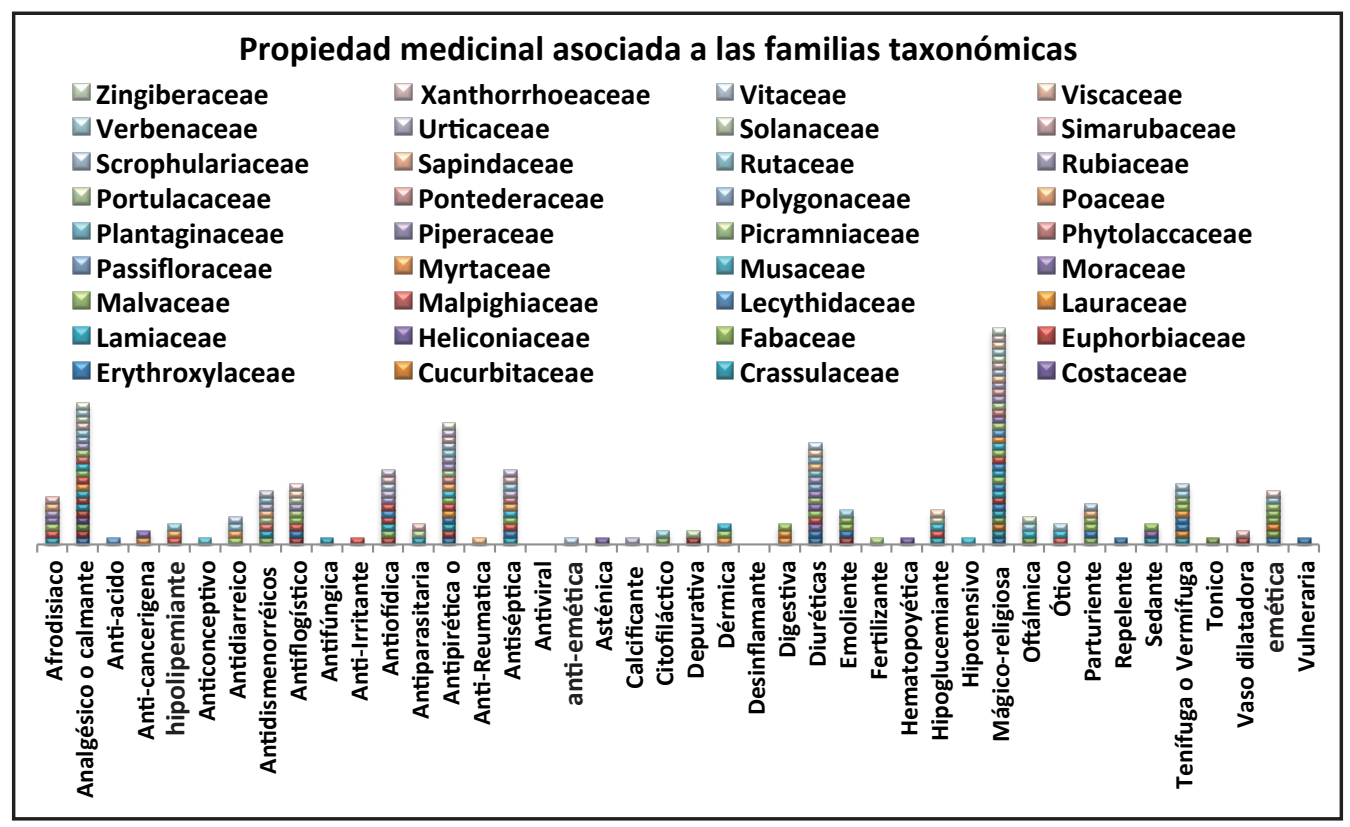

Figura 4. Categorías medicinales por familias

El análisis establece que los síntomas de la enfermedad son un indicativo de qué tipo de plantas se deben usar. Por lo que enfermedades que se caracterizan por elevar la temperatura deberán ser tratadas con plantas frías, lo que es ratificado por diferentes autores como Suárez (71), Camacho (18) y Pereachalá (73). En este sentido, autores como Velásquez (17) y Losonzcy (19) relacionan 
las enfermedades de la mitad superior del cuerpo con padecimientos por calor tratadas con plantas frías, y la mitad inferior de cuerpo con padecimientos por el frío tratadas con plantas calientes. Ejemplo de esto es el tratamiento para los cólicos con plantas calientes ya que esta es una dolencia que en la comunidad se asocia con el frío, algo que es compartido por estudios como los de Rodríguez (21), Suárez (71), Pantoja et al., (74).
La Figura 5 relaciona la posología con el tipo de plantas de acuerdo a su categoría fría o caliente. Es de resaltar que la cocción o no cocción estará dándole características a las plantas de fría o caliente, independientemente si lo son. Esto significa que una planta fría podrá adquirir características medicinales de una planta caliente si es cocinada y viceversa, lo que coincide con los reportes en los estudios de Velásquez (17), Losonzcy (19) y Camacho (18).

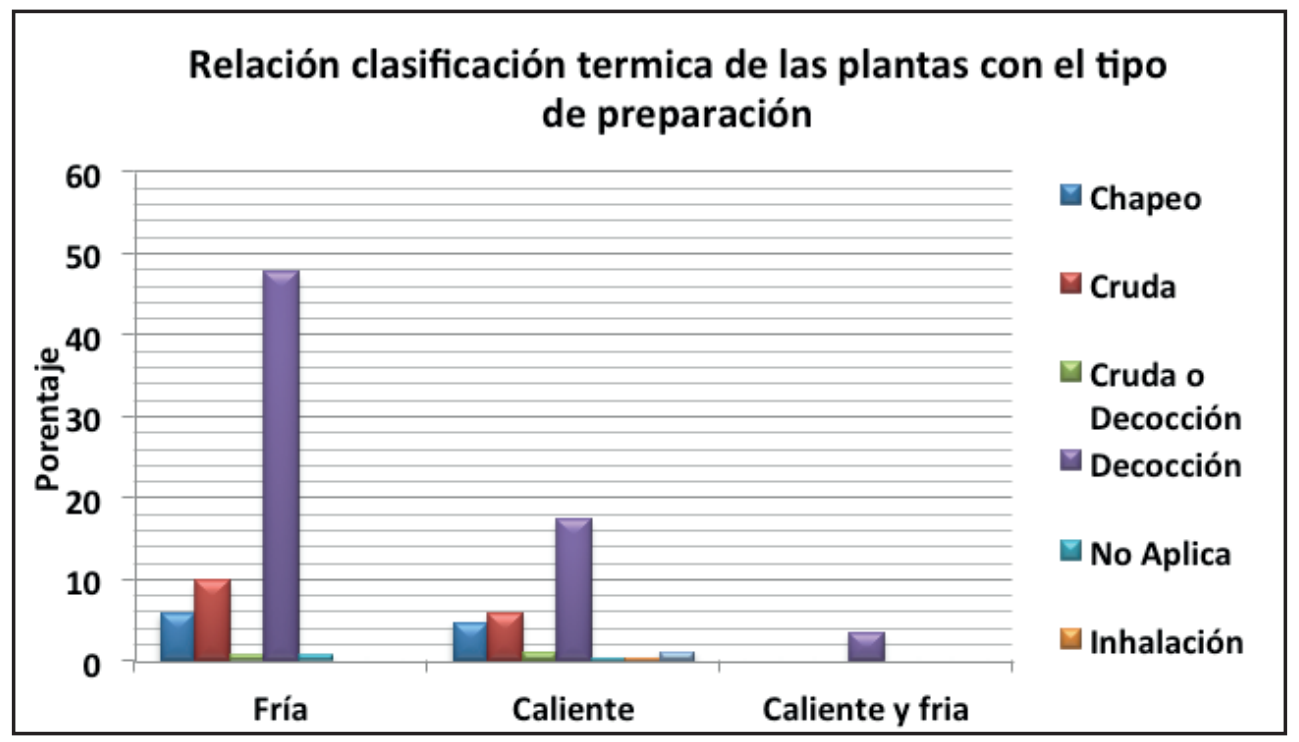

Figura 5. Porcentaje de formas de preparación por categorías térmicas

Las categorías de uso más comunes (ver Figura 4) determinan a su vez las aplicaciones más frecuentes (ver Figura 6) por lo que los tratamientos orales, baños y tópicos son los tratamientos más comunes para las afecciones que más afectan a la comunidad. Así la forma de aplicación de la planta depende de la naturaleza de la enfermedad $(75,76)$, lo que se evidencia con el reporte de plantas calificadas por la comunidad como analgésicas y antipiréticas que deben ser administradas vía oral o baños; así como plantas calificadas con usos mágico religiosos con las que no se necesita establecer ningún contacto con el cuerpo del afectado.

En la actualidad se reporta la existencia de numerosos sabedores de medicina tradicional con variadas especialidades, dentro de las especialidades sobresalen los santiguadores, curanderos, yerbateros y parteras. (20-21,77), en donde “...las modalidades más comunes de administración de los medicamentos tradicionales (...) van generalmente acompañados de rezos (secretos) como complemento o condición necesaria de su actuación terapéutica..." (30). 


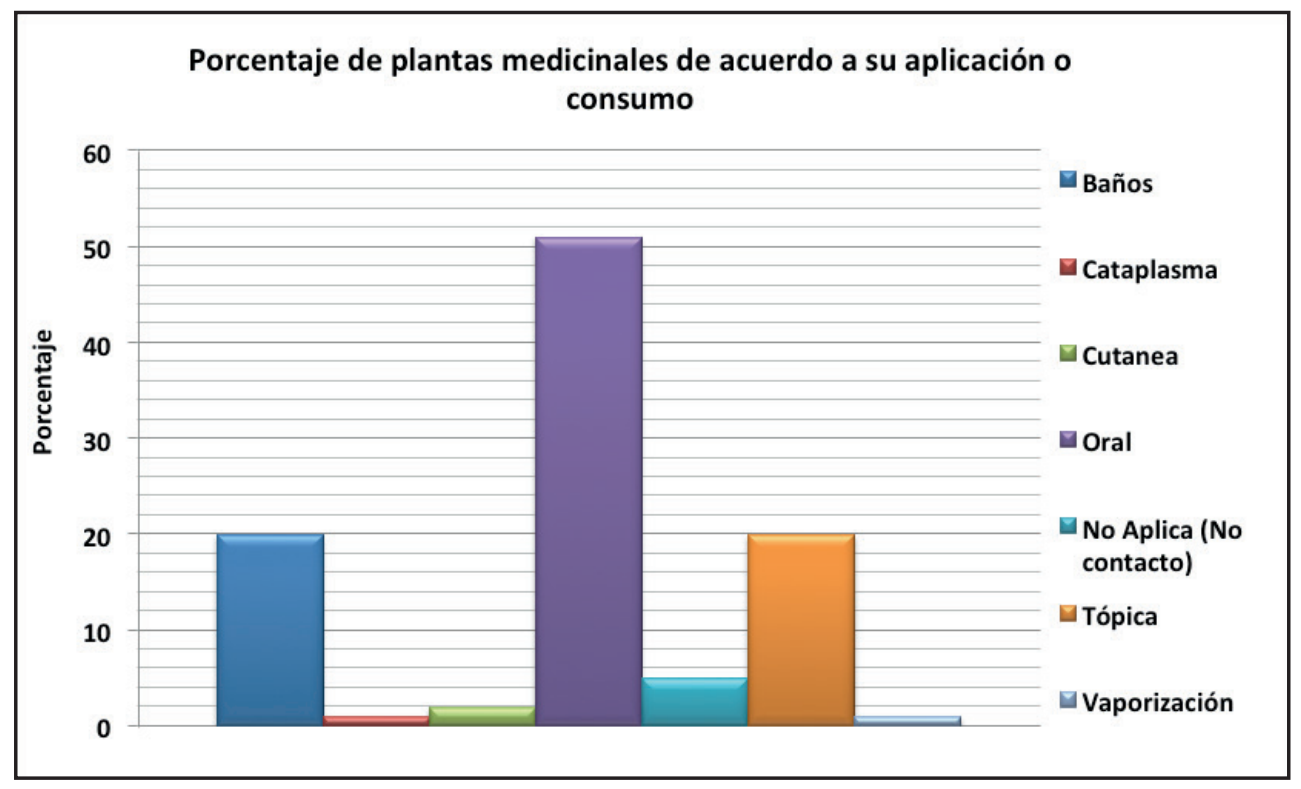

Figura 6. Porcentaje de plantas medicinales de acuerdo a su aplicación o consumo

La aplicación y preparación de diferentes partes de las plantas con valor de uso medicinal (ver Figura 7) puede estar condicionando la desaparición de ciertos usos de plantas debido a las prácticas de gestión del territorio y de los recursos naturales. El hecho que se usen plantas enteras como la segunda aplicación más frecuente es motivo de preocupación desde el punto de vista ambiental, si se tiene en cuenta que de acuerdo a los datos de campo se estableció que San Basilio de Palenque se vio afectada en el 2001 por el desplazamiento de la comunidad de la Bonga a las zonas de cultivo.
Por otra parte, se reporta que existe un conocimiento sobre el grado de toxicidad de diferentes plantas, pero la elección de las cantidades o dosificación se ciñen a preceptos culturales, donde no hay una dosificación precisa para la preparación de remedios. Este tema es motivo de preocupación ya que puede dar lugar a intoxicaciones o a efectos secundarios inesperados, por lo que se hace necesario que a partir del "sincretismo" se generen canales de comunicación entre la medicina facultativa y tradicional para clarificar y fortalecer la farmacopea local.

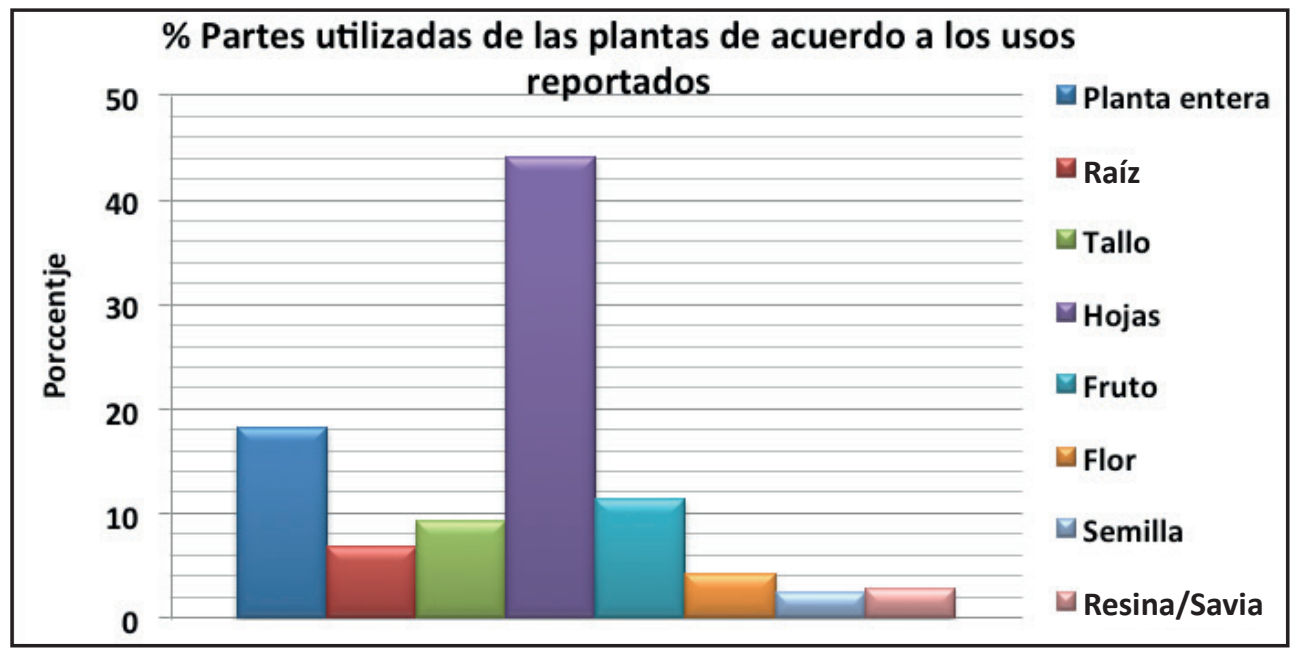

Figura 7. Porcentaje de partes utilizada para el total de usos reportados 
Lo anterior expone la importancia de establecer la presencia o ausencia de los principales grupos de metabolitos de las especies (alcaloides, quinonas, esteroides-triterpenos, flavonoides, taninos, saponinas, cumarinas y glucósidos cardiotónicos) y su relación con las actividades biológicas de las plantas; en donde la diversidad de compuesto que posee una familia de plantas justificaría la gran diversidad de usos medicinales (ver Figuras 1 y 4 ) que posee una familia en particular; tal es el caso de la familia Euphorbiaceae (tercera familia con mayor uso medicinal) la que de acuerdo al estudio de Beltrán et al., (78) tiene presencia de alcaloides, taninos, compuestos cardiotónicos y flavonoides; ejemplo de esto es que una planta perteneciente a esta familia como la Hura crepitans reporte el uso tópico de la savia para el dolor de muela, mientras que en estudios en el amazonas como el de Quintana (43) reporte su ingesta como purgante.

A pesar de esto se debe tener en cuenta que el conocimiento tradicional va más allá del ensayo y del error y que es capaz de adaptarse a cambios, sin la necesidad de intervención de otros sistemas médicos. Muestra de esto es que la malaria que no es una enfermedad endémica, ingresó a la región hace casi un siglo, por lo que posiblemente se descubrió la propiedad antimalarica de la Momordica charantia (la propiedad antimalarica se encuentra detallada en el texto de Sánchez (79) y de la Quassia amara). La propiedad antimalarica se reporta en la literatura de Quesada (80) y Díaz et al., (81), combatiendo la fiebre, uno de los principales síntomas de la enfermedad. Lo anterior expone la paradoja en las leyes colombianas al considerar con la ley 691 del 2001 las prácticas tradicionales de medicina de las comunidades indígenas como permitidas, pero no generar un estamento que legalice estas prácticas en las comunidades afrodescendientes (82).

En cuanto a la relación territorio-cuerpo humano se establece una analogía entre la relación aguaplantas (el agua regula la temperatura de la planta y le brinda salud) y sangre-cuerpo (la sangre regula la temperatura corporal y la salud humana)
$(17,19)$. En este sentido exponer la clasificación binaria frío-calor al considerar la sangre y la orina como fluidos corporales que reflejan el "calor' y el "frío", demuestra una lógica que se refleja en algunos caracteres del mundo vegetal. De esta manera las interrelaciones entre el agua y el paisaje terrestre dan una visión dinámica al paisaje (8384). Autores como Schwegler (32) establecen a la vegetación como el elemento más importante de la ritualidad, lo que para Quintana (85-86) genera una reconfiguración simbólica del espacio que debe ser tenida en cuenta para lograr una gestión sustentable del territorio.

Asimismo, se establecen lógicas que rigen el cuerpo humano y el territorio a través de los ciclos de la luna. Ejemplo de esto se da con los momentos de uso de las plantas asociadas a los purgantes, cuya preparación se prefiere sea en luna mala o biche, ya que si se hace en luna llena o buena las lombrices se encontrarán en un momento de reproducción (al igual que en el territorio este momento es ideal para generar proliferación). Lo anterior coincide con lo expuesto por Restrepo y Natividad (30) donde la luna mala o biche es ideal para preparar las parcelas de los cultivos, lo que llevado al ser humano significa el momento idóneo para empezar un tratamiento que surta efecto al preparar el cuerpo para un cambio.

\section{Conclusiones}

- Las plantas de mayor importancia o valor cultural para todos los informantes entrevistados son: Limón (Citrus sp), usada en la comunidad para enfermedades relacionadas con la circulación, gripa, diarrea, ojos, heridas, inflamación, parásitos, cólicos. Matarraton (Gliricidia sepium), usada en la comunidad para enfermedades relacionadas con el parto, brujería, fiebre y ronchas. Cagada de pájaro (Phoradendron sp) usada en la comunidad para enfermedades relacionadas con la diabetes, circulación (trombosis), inflamación, riñones y brujería. Escobilla menuda (Scoparia dulcis) usada en la comunidad para 
enfermedades relacionadas con lombrices intestinales, fiebre y la brujería. Cruceto morado (Quassia amara) usada en la comunidad para enfermedades relacionadas con el vómito, mordedura de serpiente, dolor, brujería, paludismo, gripa y la impotencia.

- Las familias vegetales más representativas son la Fabeceae, Malvaceae y Asteraceae. Esto es de especial interés porque puede ser un indicativo de su importancia en la variedad vegetal de la zona, y dado que estas familias también son representativas en estudios realizados en África, resulta pertinente establecer la historia social de estas plantas.

- Es evidente que los modelos educativos a nivel nacional presentan una escuela impregnada por una visión del mundo eurocéntrica a la que hay que descolonizar. En este sentido los estudios de tipo etnobotánico son un instrumento que puede ser utilizado para acercar a niñas, niños y jóvenes a su institución educativa y a sus raíces africanas, revalorizando una tradición cultural que recoge su identidad y que se aprende y se practica desde la infancia.

- El análisis histórico de los resultados expone un legado africano de clasificaciones térmicas con un enfoque ético de usos sobre este saber ancestral. En este sentido los resultados de campo muestran una mayor presencia de plantas consideradas como femeninas asociadas al agua o frías, lo que podría ser aprovechado por la institución educativa de la comunidad para realizar proyectos para la recuperación y preservación del río, así como para la generación de estrategias de gestión ambiental del territorio por parte de los líderes de la comunidad.

- Los africanos le transmitieron a sus descendientes saberes y técnicas sobre el mundo vegetal y animal. Estos conocimientos, que fueron utilizados para curar los males del cuerpo y los del alma, se caracterizaban por un componente experimental cuyo éxito dependía también de la interacción con los espíritus. Asimismo, es de resaltar que esta clasificación actualmente se reporta en estudios realizados con indígenas, lo que probablemente es debido a las relaciones entre africanos e indígenas.
- Existe la particularidad de que en la comunidad se considera como enfermedad la brujería y la mala suerte. Esto podría explicarse desde la percepción de la moral y el corpus mítico que se maneja dentro de la comunidad. Es así que el origen de la enfermedad pueden ser las envidias y maleficios que se hacen a través de brujos u otros medios. Debido a esto se tiene la concepción que una persona buena, generosa, respetuosa, que sabe escuchar, aprender y enseñar no estará propenso a contraer enfermedades, a no ser que otros hayan enviado enfermedades a través de la magia.

\section{Agradecimientos}

Agradezco a los sabedores Sikito, Encarnación Padilla, Adriana Márquez, Manuel Pérez, Laburgo Salgado y Concepción Hernández, por la confianza en el trabajo y los datos suministrados para la realización de la investigación. Asimismo, agradezco a la ONG MAKUNAGUA y la Universidad Distrital Francisco José de Caldas por la financiación y acceso a zona donde se realizó la investigación.

\section{Referencias}

1. Burgos, H. Medicina campesina en transición. Quito Ecuador: Editorial Abya Yala; 1992.

2. Declaración de Chiang Mai. Salve vidas salvando plantas. Tailandia; 1998.

3. OMS (Organizacion Mundial de la Salud). (1978). ALMAATA. Atención primaria de salud. Informe sobre la conferencia internacional sobre atención primaria de salud. URRS, Ginebra. Serie salud para todos; 1978: 6-12.

4. Sánchez, E., Pardo, M., Flores, M., \& Ferreira, P. Protección del conocimiento tradicional: Elementos conceptuales para una propuesta de reglamentación. Bogotá, Colombia: Instituto de investigaciones biológicas Alexander Von Humboldt; 2001.

5. Zuluaga, G., \& Correa, C. Medicinas tradicionales: introducción al estudio de los sistemas tradicionales de salud y su relación con la medicina moderna. Bogotá, Colombia: Editorial Kimpres; 2002.

6. Perdersen, D. Elementos para el análisis de los sistemas médicos. Enfoques en atención primaria. 1989; 4(1).

7. Quintana, R. "Plantas y dueños: Descripción botánica de 
plantas medicinales, formas de preparación y cosmovisión. España: ditorial académica española; 2015.

8. Anderson, E. Why is humoral medicine so popular? Social Science \& Medicine; 1987; 25(4): 331-7.

9. Weller, S., \& Baer, R. Intra- and intercultural variation in the definition of five illnesses: AIDS, diabetes, the common cold, empacho, and mal de ojo. Cross-Cultural Research. 2001;35(2): 201-206.

10. Colson, A., \& Armellada, C. An Amerindian derivation for Latin American creole illnesses and their treatment. Soc Sci Med. 1983;17(17):1229-48.

11. Díaz, S., \& Mantilla, L. La terapéutica en el Nuevo Reino de Granada. Un recetario Franciscano del Siglo XVIII. Bogotá, Colombia: Academia Colombiana de Ciencias Exactas, Físicas y Naturales; 2002. Publicación Especial No. 7.

12. Friedemann, N., \& Patiño, C. Lengua y sociedad en el Palenque de San Basilio. Bogotá: Publicaciones del Instituto Caro y Cuervo. LXVI; 1983.

13. Villazaki, B. Bantu concepts in Medicine. Journal of the National Medical Association. 1955;47(5): 308-311.

14. Conco, M. The african Bantu traditional practice of medicine: some preliminary observations. Social science \& medicine.1972;6(3): 283-322.

15. Coral, L. Representaciones y discursos de la medicina tradicional en la comunidad negra de Barbacoas, Narińo. Tesis para optar al título de Antropólogo. Facultad de Ciencias Humanas, Departamento de Antropología. Bogotá: Universidad Nacional de Colombia; 1998.

16. Zuluaga, G. La Botella Curada: un estudio de los sistemas tradicionales de salud en las comunidades afrocolombianas del Chocó Biogeográfico Amazon Conservation Team, Instituto de Etnobiología, Universidad del Bosque. Da Vinci Editores: Bogotá; 2003.

17. Velásquez, R. La medicina popular en la Costa colombiana del Pacífico. Revista colombiana de Antropología.1957;6:95-258.

18. Camacho, J. Mujeres, zoteas y hormigas arrieras: prácticas de manejo de flora en la costa Pacífica chocoana Zoteas. Biodiversidad y relaciones culturales en el Chocó Biogeográfico; 2001: 35-58.

19. Losonzcy, A. De lo vegetal a lo humano: un modelo cognitivo afroafrocolombiano del Pacífico. Revista Colombiana de Antropología. 1993: 33-57.

20. Ardón, N., Hernández, A., Sáenz, J., Ruíz, L., \& Ternera, J. Sistemas de Salud de las Comunidades Indígenas y Negras de Colombia estudiadas por la Gran Expedición Humana. Pontificia Universidad Javeriana. Bogotá: Fundación Cultural Javeriana de Artes Gráficas -JAVEGRAF;1996.

21. Vásquez, C. Conceptos que orientan la clasificación por categorías térmicas de las plantas medicinales, en el Sistema Tradicional de Salud de la Comunidad Afrodescendiente de Palenque San Basilio, Bolívar, Colombia. Bogotá: Tesis de grado para optar por el titulo de Magister en Medicina Alternativa. Universidad Nacional de Colombia; 2012.
22. Borrego, M. Palenques de negros en Cartagena de Indias a finales del siglo XVII. Sevilla: Escuela de Estudios HispanoAmericanos; 1973.

23. Friedemann, N., \& Patińo, C. Lengua y sociedad en el Palenque de San Basilio. Bogotá: Publicaciones del Instituto Caro y Cuervo. LXVI; 1983:180-250.

24. Arrazola, R. Palenque. Primer pueblo libre de América. Cartagena: Casa Editorial Tercera edición; 2003.

25. Navarrete, M. San Basilio de Palenque. Memoria y Tradición. Surgimiento y avatares de las gestas cimarronas en el Caribe Colombiano. Santiago de Cali: Programa Editorial Universidad del Valle . 2008.

26. Soto, D., Balanzó, A., Herrera, B., Ondóńez, G., Vargas, J., Marrugo, L., \& Pérez, M. San Basilio de Palenque, Colombia: Cultura presente, territorio ausente. Chile: Centro Latinoamericano para el Desarrollo Rural -RIMISP-: Estudios de la Sociedad Rural, 35. Perú: Instituto de Estudios Peruanos -IEP-;2009.

27. Balanzo, A., Herrera, B., Peres, M., \& Marrugo, L. Estudio de caso san Basilio de palenque. Colombia patrimonio oral e inmaterial de la humanidad. Facultad de finanzas, gobierno y relaciones internacionales. Bogotá: Universidad externado de Colombia; 2007.

28. Mogollón, M.”El palenque de San Basilio", conferencia dictada en Valledupar; 1992.

29. Cassiani, R., Guerrero, C., \& Pérez, J. Palenque: Historia libertaria, cultura y tradición . Cartagena: Casa Editorial S.A; 2008.

30. Restrepo, E., \& Natividad, J. San Basilio de Palenque: Caracterizaciones y Riesgos del Patrimonio Intangible. Universidad del Magdalena; 2002:58-69.

31. Valencia, J. Survivances Bantu au Chocó (Colombie). Tesis para optar al título de doctor en Antropología. Universite Nationale Du Zaire Campus Lubumbashi; 1977(1 y 2) .

32. Schwegler, A. "Chi Ma nKongo": lengua y rito ancestrales en El Palenque de San Basilio (Colombia). Madrid Espańa: Editorial Iberoaméricana; 1996.

33. Adu-Tutu, M., Afful, Y., Asante-Appiah, K., Leberman, D. H., \& Elvinlewis, M.). Chewing Stick Usage in Southern Ghana. Econ Bot.1979:320-328.

34. Phillips, O., \& Gentry, A.The Useful Plants of Tambopata, Perú: I.Statistical Hypotheses Test with a New Quantitative Technique; 1993.

35. Phillips, O. Some quantitative methods for analyzing ethnobotanical knowledge. New York : the New York botanical garden; 1996.

36. Farnsworth, N., Akerele, O., Bingel, A., Soejarto, D., \& Guo, Z. Medicinal Plants in Therapy. Bull. of the World Health Org. 1985;63(5): 965-981.

37. Khafagi, I., \& Dewedar, A. The Efficiency of Random versus Ethnodirected Research in the Evaluation of Sinaí Medicinal Plants for Bioactive Compounds. J. of Ethnopharm. 2000;71:365-376. 
38. Quintana, R. El "verdadero" guardian del oro verde verde, estudio etnobotánico en la comunidad indígena de Macedonia. Bogotá: Tesis de grado para optar por el titulo de Licenciado en Biología. Universidad Distrital Francisco José de Caldas; 2009.

39. Höft, M., Barik, S., \& Lykke, A. Quantitative Ethnobotany Applications of multivariate and statistical analyses in ethnobotany. People and plants working paper; 1999:49.

40. Rodríguez , G., Banda-R, K., Reyes, S., \& Estupiñán, A. Lista comentada de las plantas vasculares de bosques secos prioritarios para la conservación en los departamentos de Atlantico y Bolivar (Caribe colombiano).Especial Bosque Seco en Colombia. Biota Colombiana. 2012;13(2):7-39.

41. Nates, B. De lo Etno a lo Botánico: Algunas reflexiones sobre lo etnobotánico dentro del marco de las etnociencias. Luna Azu;2006:73-86.

42. Germosén Robineau, L. Farmacopea Vegetal Caribeña (Tercera edición ampliada y actualizada ed.). (L. Germosén Robineau, Ed.) Yucatán, México: TRAMIL, Centro de Investigación Científica de Yucatán, A.C. Mérida; 2014.

43. Quintana, R. Estudio de plantas medicinales usadas en la comunidad indígena Tikuna del alto Amazonas, Macedonia. NOVA: Publicación científica en ciencias biomédicas. 2012;10(18): 179-191.

44. Bejarano, M. Estudio de las plantas Medicinales utilizadas por la Comunidad indígena Camaritagua (Amazonas Colombia). Tesis de grado (Biología). Bogotá: Universidad Nacional de Colombia. 2003

45. Palacios, P. Análisis de los usos y formas de manejo de algunas especies vegetales empleadas por las Comunidades Anoque, Huitoto y Miraña asentadas en la ribera del rio Caquetá. Colombia Amazónica; 1986.

46. Milliken, W., \& Albert, B. The use of medicinal plants by the Yanomi Indians of Brazil. Economyc Botany. 1997: 264-278.

47. Aces, R. Plantas útiles de las Antillas; guía práctica de los usos industriales, comerciales, medicinales y populares de las plantas silvestres y cultivadas de las Antillas. Cuba: Habana, G. Martinez Amengual; 1939.

48. Ayensu, E. Medicinal Plants of West Africa . Michigan: Reference Publications; 1978.

49. Ayensu, E. Medicinal Plants of the West Indies . Michigan: Reference Publications; 1981.

50. Davis, W. The Ethnobiology of the Haitian Zombie. Journal of Ethnopharmacology, 1983;9(1): 85-104.

51. Burkill, H. Useful Plants of West Tropical Africa, (Vols. Botanic Gardens, Kew. Vol. 1, 1985 (Botanical Families A-D); 19852000vol. 2, 1994 (botancal families E-I); vol. 3, 1995 (botanical families J-L); vol. 4, 1997 (botanical families M-R); vol. 5, 2000 (botanical familifamilies S-Z). Royal Botanic Gardens.

52. Honeychurch, P. Caribbean Wild Plants and their Uses. London: Macmillan Education; 1986.

53. Jordan, P. Herbal Medicine and Home Remedies. Bahamas: Nassau Guardian Print. Press; 1986.
54. Oliver-Bever, B. Medicinal Plants in Tropical West Africa . Cambridge: Cambridge Universty Press; 1986.

55. Abbiw, D. Useful Plants of Ghana: West African uses of wild and cultivated plants. London: Intermediate Technology Publications; 1990

56. Price, R. Subsistence on the plantation periphery: crops, cooking and labour among eighteenth-century Suriname maroons. Slavery and Abolition.1991;12(1): 107-127.

57. Roig, J. Plantas medicinales aromaticas o venenosas de cuba. Havana: Cientifico-Tecnica;1991 (2).

58. Rashford, J. Arawak, Spanish and African contributions to Jamaica's settlemen vegetation. Jamaica Journal. 1993;24(3):17-23.

59. Brusell, D. Potions, Poisons and Panaceas: An Ethnobotanical Study of Montserrat . Illinois: Southern Illinois University Press; 1997.

60. Thomas, T., O’Reilly, R., \& Davis, O. Traditional Medicinal Plants of St Croix, St Thomas and St John. A Selection of 68 Plants. St Croix: University of the Virgin Islands;1997.

61. Voeks, R. Sacred Leaves Of Camdomblé. Austin: University of Texas; 1997.

62. Madge, C. Therapeutic landscapes of the Jola, The Gambia, West Africa. Health \& Place. 19984;(4):293-311.

63. Martin, F., Ruberte, R., \& Meitzner, L. Edible Leaves of the Tropics. Florida: Echo Press; 1998.

64. Lowe, H., Payne-Jackson, A., Beckstrom-Sternberg, S., \& Duke. JJamaica’s Ethnomedicine: Its potential in the healthcare system. Jamaica: Canoe Press, University of the West Indies, Kingston; 2000.

65. Mors, W., Rizzini, C., Pereira, N., \& Defilipps, R. Medicinal Plants of Brazil (Medicinal Plants of the World). Algonac, Michigan; Reference Publications; 2000.

66. Carney, J. African Traditional Plant Knowledge in the CircumCaribbean Region. Journal of Ethnobiology. 2003;23(2): 167-185.

67. Aya, A. Demografía histórica de la trata por Cartagena de Indias, 1533-1810, en Geografía Humana de Colombia, tomo VI: Los Afrocolombianos. Bogotá: Instituto Colombiano de Cultura Hispánica; 1998.

68. De Surgy, A. "Les capacités d'évolution de la religion traditionnelle adja-évhé" L'invention religieuse en Afrique. París: Editions Karthala/ACCT; 1993.

69. Maya, L. Botánica y medicina africanas en la nueva granada, siglo XVII. Historia Crítica. 2001;2:4-42.

70. Nates Cruz, B., Cerón, P., \& Hernández, H. Las plantas y el territorio: Clasificaciones, usos y concepciones en los Andes Colombianos. Popayan (Colombia): Corporación madremonte; 1994.

71. Suárez, S. Baudosueños convivencia y polifonía ecológica. Informe finaldel área etnobotánica. Etnobotánica afrobaudoseña;1996.

72. Escalante, A. El Palenque de San Basilio. Una comunidad de descendientes de negros cimarrones. Editorial Mejoras; 1979. 
73. Pereachalá, R. Del Conocimiento Tradicional. En: En torno al conocimiento tradicional Instituto de Investigaciones Ambientales del Pacífico IIAP. Publicaciones Ébano; 2006.

74. Rodríguez, D. Usos y costumbres en la medicina tradicional en comunidades negras de la costa caucana. En: Pantoja, J.O. et al. 2008. Tras el conocimiento ancestral afrocolombiano. Encuentros de saberes en medicina tradicional del Pacífico Caucano . Instituto de InvestigPacífico - IIAP. Editorial Valformas Ltda; 2008.

75. Glemboski, L. Ethnobotany of the Tikuna, Amazonas, Colombia. Bogotá: Instituto de Ciencias Naturales Universidad Nacional de Colombia; 1983.

76. Díaz, M. Estudio etnobotánico de las plantas empleadas por dońa Romelia, Terapeuta Tradicional del Municipio de Mocoa (Putumayo). Bogotá, Colombia: Tesis de grado (Biología). Pontificia Universidad Javeriana; 1998.

77. Guerrero, C., Cassiani, R., Pérez, J., Pérez, J., \& Restrepo, E. Palenque de San Basilio. Obra maestra del patrimonio intangible de la humanidad. Bogotá: Ministerio de Cultura / Instituto Colombiano de Antropología e Historia; 2002.

78. Beltrán, C., Fredyc, D., \& Harold, G. Tamizaje fitoquímico preliminar de especies de plantas promisorias de la costa atlántica colombiana. Revista Cubana de Plantas Medicinales. 2013;18(4):619-631.

79. Sánchez, J. Diccionario de plantas medicinales. Editorial Ta-BooK Editorial especializada en terapias naturales. 2013; ISBN: 978-84-941386-1-4.
80. Quesada, A. Plantas al servivio de la salud: Plantas Medicinales de Costa Rica y Centro America. Arena Trans America; 2008.

81. Díaz, R., Hernández, L., Ocampo, R., \& Cicció, J. Domesticación y fitoquímica de quassia amara (simaroubaceae) en el trópico húmedo de Costa Rica; 2006.

82. Congreso de la República Colombiana. Ley 691 2001: Mediante la cual se reglamenta la participación de los Grupos Étnicos en el Sistema General de Seguridad Social en Colombia; 2001.

83. Van der Hammen, M. El manejo del mundo, naturaleza y sociedad entre los Yukuna de la amazonia colombiana. Estudios en la amazonia Colombiana. Bogotá, Colombia.: Tropembos y tercer mundo editores; 1992.

84. Quintana, R. Sombras Invisibles: Las representaciones de niños y niñas Miraña en una comunidad Tikuna. Revista Chilena de Antropología Visual.2011; (17): 92-111.

85. Quintana, R. Reconfiguración simbólica del territorio en una comunidad Indígena Amazónica. Revista Chilena de antropología visual. 2013; 22:92-114.

86. Millan, J. and L. Yunda (2014). “An Open-Access Web-based medical image atlas for collaborative Medical image sharing, processing, Web Semantic searching and analysis with uses in medical training, research and second opinion of cases." Nova 12(22): 143-150. 